\title{
Applications of Carbon in Rechargeable Electrochemical Power Sources: A Review
}

\author{
Jakub Lach $^{1}$, Kamil Wróbel ${ }^{1, * \mathbb{D}}$, Justyna Wróbel ${ }^{2}$ and Andrzej Czerwiński ${ }^{3}$ \\ 1 Łukasiewicz Research Network-Industrial Chemistry Institute, Rydygiera 8 str., 01-793 Warsaw, Poland; \\ jakub.lach@ichp.pl \\ 2 Łukasiewicz Research Network-Institute for Engineering of Polymer Materials and Dyes, \\ Marii Skłodowskiej-Curie 55, 87-100 Toruń, Poland; justyna.wrobel@impib.lukasiewicz.gov.pl \\ 3 Faculty of Chemistry, University of Warsaw, Pasteura 1, 02-093 Warsaw, Poland; aczerw@chem.uw.edu.pl \\ * Correspondence: kamil.wrobel@ichp.pl
}

Citation: Lach, J.; Wróbel, K.; Wróbel, J.; Czerwiński, A. Applications of Carbon in Rechargeable Electrochemical Power Sources: A Review. Energies 2021, 14, 2649. https://doi.org/10.3390/ en14092649

Academic Editor: Merce Segarra

Received: 26 March 2021

Accepted: 27 April 2021

Published: 5 May 2021

Publisher's Note: MDPI stays neutral with regard to jurisdictional claims in published maps and institutional affiliations.

Copyright: (c) 2021 by the authors. Licensee MDPI, Basel, Switzerland. This article is an open access article distributed under the terms and conditions of the Creative Commons Attribution (CC BY) license (https:// creativecommons.org/licenses/by/ $4.0 /)$.
Abstract: Rechargeable power sources are an essential element of large-scale energy systems based on renewable energy sources. One of the major challenges in rechargeable battery research is the development of electrode materials with good performance and low cost. Carbon-based materials have a wide range of properties, high electrical conductivity, and overall stability during cycling, making them suitable materials for batteries, including stationary and large-scale systems. This review summarizes the latest progress on materials based on elemental carbon for modern rechargeable electrochemical power sources, such as commonly used lead-acid and lithium-ion batteries. Use of carbon in promising technologies (lithium-sulfur, sodium-ion batteries, and supercapacitors) is also described. Carbon is a key element leading to more efficient energy storage in these power sources. The applications, modifications, possible bio-sources, and basic properties of carbon materials, as well as recent developments, are described in detail. Carbon materials presented in the review include nanomaterials (e.g., nanotubes, graphene) and composite materials with metals and their compounds.

Keywords: energy storage; carbon; nanomaterials; lead-acid batteries; lithium-ion batteries; lithiumsulfur batteries; sodium-ion batteries; supercapacitors

\section{Introduction}

The development of technology, exponentially accelerating in modern times, is closely related to rising energy needs. Moreover, the human population is constantly rising, reaching 7.8 billion in 2020 according to the UN [1]. The changes in population are leading to a further increase in energy demands. This growing demand is not without influence on the natural environment. Recent increases in pollution and $\mathrm{CO}_{2}$ emissions are causing a gradual, global shift toward more sustainable energy sources than currently widespread fossil fuels. For example, the European Union aims to be climate-neutral by 2050, as presented in the European Commission's European Green Deal [2]. This transition to renewable energy sources requires efficient energy storage. Energy production by renewable sources is characterized by a variable output and inconsistent behavior. As a result of these properties, there is a growing demand for fast and cheap energy storage, which can be used to capture the excess energy generated during the periods of high production. This stored energy can then be released when required by a drop in production or a rise in energy usage.

In recent times, there has been great interest in developing materials that will allow effective and economically viable energy storage. This goal can be realized by improvements in currently known power sources, as well as by introducing completely new solutions. One of the materials that is often used during development of such technologies is carbon. 
It is used in various energy storage technologies, including primary and secondary batteries, fuel cells, flow batteries, and capacitors [3-8]. Carbon is a very versatile element, capable of forming various types of bonds and compounds, leading to its very rich organic chemistry. At the same time, even in its elemental form, it can create many different allotropic forms with interesting physical and chemical characteristics. Moreover, recent advances in nanotechnology have opened new avenues of carbon usage [9-11]. Carbon nanomaterials have very unique properties, further broadening the possibilities of carbon application in energy storage. The versatility of carbon allows it to find use in a wide range of electrochemical power sources.

The present review describes the uses of carbon in its elemental form in modern rechargeable batteries. The focus of the paper is placed on lithium-ion and lead-acid batteries, as the currently most popular battery types on the market [12]. At the same time, some of the promising technologies that can replace them in the future are discussed, namely, lithium-sulfur and sodium-ion batteries, as well as supercapacitors. Recent developments and characteristics of the carbon materials used in the mentioned power sources are presented.

The described subjects are of a great interest to the scientific community. According to Scopus [13], there have been almost 23,000 papers regarding the topics "lithium-ion" and "carbon". There have also been many papers in the areas of other battery types; for a search combination of "carbon" and "sodium-ion", there were over 18,000 studies, while there were almost 18,000 for a search combination involving "lead-acid" and similar number for a search combination involving "supercapacitor". The joint topics of "lithium-sulfur" and "carbon" have led to over 5000 works. Additionally, in the years 2017-2020, the number of published papers grew annually for each of these subjects.

Selected power sources have different characteristics, such as specific energy, specific power, cycle life, and cost. These variations result in diverse applications found for these sources. A summary comparing the properties of the power sources described in this review is presented in Table 1.

Table 1. Comparison of different rechargeable electrochemical power sources [14-24].

\begin{tabular}{|c|c|c|c|c|c|}
\hline & \multicolumn{5}{|c|}{ Rechargeable Electrochemical Power Source } \\
\hline & Lead-Acid Batteries & Lithium-Ion Batteries & $\begin{array}{l}\text { Lithium-Sulfur } \\
\text { Batteries }\end{array}$ & $\begin{array}{l}\text { Sodium-Ion } \\
\text { Batteries }\end{array}$ & Supercapacitors \\
\hline $\begin{array}{l}\text { Specific energy } \\
(\mathrm{Wh} / \mathrm{kg})\end{array}$ & $35-50$ & 80-180 & $150-350$ & $75-150$ & $0.05-10$ \\
\hline $\begin{array}{l}\text { Specific power } \\
(\mathrm{W} / \mathrm{kg})\end{array}$ & $150-400$ & 200-1000 & $100-300$ & up to 1500 & $2000-10,000$ \\
\hline Cycle life & $\begin{array}{l}\text { Moderate (up to } \\
1000 \text { cycles, } 2000 \\
\text { cycles for special } \\
\text { designs) }\end{array}$ & $\begin{array}{l}\text { High (up to } 3000 \\
\text { cycles) }\end{array}$ & $\begin{array}{l}\text { Low (up to a few } \\
\text { hundred cycles) }\end{array}$ & $\begin{array}{l}\text { Moderate (up to } \\
1000 \text { cycles) }\end{array}$ & $\begin{array}{l}\text { Very high (over } \\
10,000 \text { cycles) }\end{array}$ \\
\hline $\begin{array}{l}\text { Self-discharge } \\
\text { rate }\end{array}$ & $\begin{array}{l}\text { Low (2-8\% per } \\
\text { month) }\end{array}$ & $\begin{array}{c}\text { Low }(2-10 \% \text { per } \\
\text { month) }\end{array}$ & $\begin{array}{l}\text { Moderate (over } \\
15 \% \text { per month) }\end{array}$ & $\begin{array}{l}\text { Low (small \% per } \\
\text { month) }\end{array}$ & $\begin{array}{l}\text { High (over } 10 \% \text { per } \\
\text { day) }\end{array}$ \\
\hline $\begin{array}{l}\text { Approximated } \\
\text { cost per unit } \\
\text { energy } \\
\text { (USD/kWh) }\end{array}$ & 80-200 & $170-350$ & $\begin{array}{l}\text { 200 } \\
\text { (estimated to be } \\
\text { lower than } \\
\text { lithium-ion } \\
\text { batteries) }\end{array}$ & $\begin{array}{l}\text { Estimated as } \\
\text { lower than } \\
\text { lithium-ion } \\
\text { batteries }\end{array}$ & Over 10,000 \\
\hline $\begin{array}{c}\text { Typical } \\
\text { applications }\end{array}$ & $\begin{array}{l}\text { SLI batteries; energy } \\
\text { storage systems } \\
\text { (power walls, UPS } \\
\text { systems); vehicular } \\
\text { applications (micro- } \\
\text { and mild-hybrid } \\
\text { electric vehicles) }\end{array}$ & $\begin{array}{l}\text { Portable electronics; } \\
\text { vehicular applications } \\
\text { (hybrid-electric, } \\
\text { electric, and } \\
\text { plug-in-hybrid electric } \\
\text { vehicles); energy } \\
\text { storage systems }\end{array}$ & $\begin{array}{c}\text { Potentially } \\
\text { electric vehicles; } \\
\text { portable } \\
\text { electronics }\end{array}$ & $\begin{array}{l}\text { Potentially } \\
\text { electric vehicles; } \\
\text { power tools; } \\
\text { small energy } \\
\text { storage systems } \\
\text { (home storage) }\end{array}$ & $\begin{array}{c}\text { Portable electronics; } \\
\text { voltage stabilizers; } \\
\text { potentially vehicular } \\
\text { applications } \\
\text { (start-stop and } \\
\text { micro-hybrid electric } \\
\text { vehicles) }\end{array}$ \\
\hline
\end{tabular}




\section{Lead-Acid Batteries}

Lead-acid batteries are used in automotive, traction, and backup applications and are among the biggest parts of the rechargeable battery market, comparable to lithium-ion batteries. The value of produced lead-acid and lithium batteries has almost been equal in recent years; however, taking into account the total energy, lead-acid batteries account for over $70 \%$ of the market [12]. Despite the progress in the construction of newer battery types, lead-acid batteries are still a technology that is very cost-effective, proven, reliable, and easily recyclable [3,25]. Carbon is one of the materials commonly used in lead-acid batteries. There are three main parts of these batteries that can be improved by the usage of elemental carbon: the active mass, the current collectors, and the negative plate as a whole [26-28].

First, carbon can be used as an additive to both the negative and the positive active mass (NAM and PAM, respectively). However, the use of carbon in NAM, as part of a so-called "expander", is much more common and is currently a very widespread practice $[25,28]$. Such an addition to NAM during its preparation improves the electrochemical properties of the finished battery, including its cycle life, charge efficiency, and specific energy $[25,29]$. This addition is especially important when the battery is working at high-rate charge/discharge currents. For example, lead-acid batteries with carbon additives show a marked improvement in the high-rate partial stage of charge (HRPSoC) conditions, which are relevant for hybrid vehicle usage [28,30]. Figure 1 presents the increase in the number of completed cycles for batteries with carbon additives in NAM compared to a blank battery without such additives.

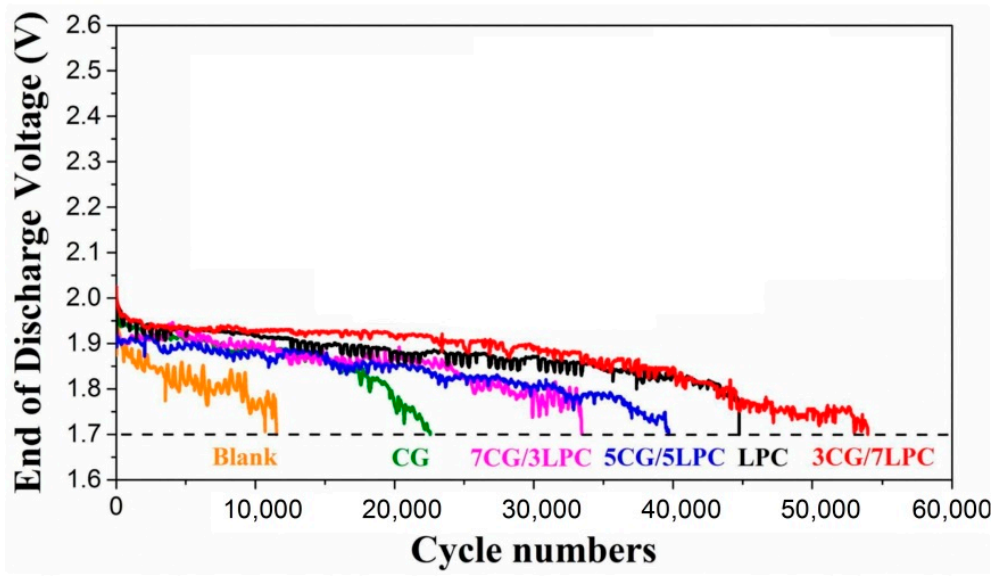

Figure 1. Comparison of number of cycles completed in HRPSoC conditions for lead-acid batteries with various carbon additives, conductive graphene (CG), and lead-doped porous carbon (LPC) with different mass ratios. HRPSoC regime: charge at C/5 for $90 \mathrm{~s}$ (voltage limit of $2.35 \mathrm{~V}$ ), rest for $10 \mathrm{~s}$, discharge at C/5 for $60 \mathrm{~s}$, and rest for $10 \mathrm{~s}$. Adapted from [31] with permission from Elsevier.

There have been a few proposed mechanisms of beneficial carbon influence as an NAM additive, but three are most often recognized [27,28,32,33]. First, carbon can change the structure of the active mass and form a conductive skeleton inside it. When NAM is discharged, metallic lead is transformed into nonconductive lead(II) sulfate(VI). Addition of carbon helps the active mass to retain some conductivity and provides a larger active surface area, even when deeply discharged. The second mechanism is a mechanical restriction of the growth of lead(II) sulfate(VI) crystals. The kinetics of dissolution of these crystals during recharging depends on their size. Bigger crystals have lower surface area compared to their volume; thus, their transformation into lead is slower. During a typical charging process of the battery, some of the larger crystals are not reduced fast enough and remain as lead(II) sulfate(VI). This process of plate sulfation leads to some of the active mass not taking part in charge/discharge processes and gradual loss of capacity of the battery. A carbon additive in NAM relieves this problem, as it becomes incorporated into 
the pores of the mass, which allows it to physically restrict the available space in them and inhibit the growth of lead(II) sulfate(VI) crystals. This steric hindrance to sulfation improves the cyclability of the battery. In the third mechanism, the carbon additive in NAM can work as a capacitor, storing additional energy in its electric double layer. This process is faster than the typical faradaic process in the active mass. The capacitive effect of carbon additives leads to improved charge acceptance and power when using high-rate currents $[27,28,32,33]$.

Types of carbon material often used as an NAM additive include activated carbon, carbon black, graphitic powder, graphene, or nanomaterials (e.g., nanotubes, graphene, nanofibers) [32-36]. Nanotubes can be single- or multiwalled, and their surface can be modified to further improve their properties [36,37]. Some of the important properties of carbon materials used as additives are surface area, conductivity, affinity to lead, porosity, hydrogen evolution overpotential, and surface chemistry. Typically used carbon additives have specific surface area and capacitance greater by orders of magnitude than the NAM. When working as a capacitor, an addition of $2 \mathrm{wt} . \%$ carbon with a specific capacitance of around $200 \mathrm{~F} / \mathrm{g}$ can provide around 1-2\% of the total capacity of the plate, which is enough when charging/discharging for a short time at high-rate currents [29]. The conductivity of the material depends, among other factors, on the presence of connected domains of carbon atoms with a graphite structure. Amorphous carbons with small particle size, e.g., activated carbon, are in general characterized by worse conductivity [28]. Conductivity is not an important parameter regarding the steric effect of additives on sulfation, but the carbon material needs to be able to be properly mixed with the active mass.

The correct preparation of the active mass when mixing the paste and increased hydrogen evolution are two important aspects that need to be considered when using carbon additives. Carbon materials change the physical and chemical properties of the active mass. In order to achieve a mass with appropriate characteristics for pasting plates, some modifications in the pasting process or composition of the mix may be required. Addition of carbon also leads to acceleration of the hydrogen evolution reaction, resulting in losses of the electrolyte during charging of the batteries. These additives in general have lower hydrogen evolution overpotentials than lead; moreover, they can contain impurities and increase the active surface area, further facilitating the oxidation of hydronium ions.

One of the ways to alleviate the hydrogen evolution problem involves new types of composite carbon materials doped with heteroatoms. Modification of the structure of the carbon material by doping with metals with high hydrogen evolution overpotential allows limiting the reaction rate of hydrogen evolution, while retaining the positive influence of carbon [37-39]. Doping with nonmetals, e.g., nitrogen or phosphorus, can also provide similar benefits by modifying the electron density on carbon atoms and the strength of their bonds with hydrogen [40,41].

Carbon additives to NAM are a very important part of the lead-acid battery technology. In the past, they solved the problems of premature capacity loss introduced when organic separators were replaced by synthetic materials [25]. Today, their usage allows surpassing the limitations appearing when lead-acid batteries work in an HRPSoC regime. This topic is very important when taking into account the current energy transformation and spread of electric and hybrid vehicles.

Carbon materials can also be used as an additive to PAM. However, this practice is not so widespread, as they are less stable in the working conditions of PAM and can breakdown during the first cycles of life of the battery. Their positive influence on cycle life is also less pronounced than in the case of NAM or even not observable. On the other hand, there is some research indicating an improvement in the behavior of PAM when some carbon additives are used. An increase in cycle life and capacity when carbon fiber was added was reported [23,42]. The additives can reduce PAM softening and shedding, as well as improve conductivity and porosity $[23,42,43]$. There are fewer studies in this area than in the case of NAM additives. Nonetheless, the research is still ongoing, and introducing new types of carbon materials, including composites and nanomaterials, gives an opportunity 
to further improve PAM properties [34,44,45]. Additionally, carbon used as a paste additive can be based on biological sources. Improvements in the characteristics of both PAM and NAM were reported when using porous rice husk-based carbon as an additive [46,47].

Another part of a lead-acid battery, namely, current collectors, can also be improved by using carbon materials. Typically, a collector is a grid cast from lead alloy. It can be replaced by a much lighter reticulated carbon material, e.g., reticulated vitreous carbon (RVC), as proposed by Czerwiński et al. [48-50]. When used in this role, glassy carbon materials are resistant to corrosion while working in the negative plate [51]. On the other hand, the positive plate of the lead-acid battery experiences conditions causing corrosion of reticulated carbon collectors. To use the carbon collectors in this environment, they need to be protected by a corrosion-resistant layer, for example, a galvanically deposited thin layer of lead $[49,52]$. This protective layer improves both resistance to corrosion and mechanical properties. Using the reticulated carbon collectors can lead to a decrease in weight, an increase in specific energy and active mass utilization, better mechanical support for the mass, and longer cycle life [26,53-56].

Different forms of carbon can be used as the reticulated current collector. First experiments mainly concerned RVC [49,50,52]. Further studies investigated different materials, such as pitch-based foams [57,58], graphite foams [56], graphite foils [59], graphite punched sheets [60], polymer-graphite composites [61], honeycomb carbon structures [55,62,63], carbon fiber felt [64], or conductive porous carbon [54]. In general, for the mentioned materials, negative plates showed good results regarding capacity and cycle life. The results for positive plates were more mixed. Better cycle life than in comparable standard batteries could be achieved when the positive collectors were prepared using suitable materials and optimal lead (or lead alloy) coatings [54]. Some of the solutions already available on the market use reticulated carbon collectors, e.g., the Oasis battery produced by Firefly Energy in USA. The use of new types of lighter, reticulated current collectors is a promising solution which improves the main weakness of lead-acid batteries: their low specific capacity. At the same time, this new technology can lead to improvements in other areas, such as cycle life, temperature performance, or environmental impact. Figure 2 shows the differences between various types of standard and reticulated collectors.
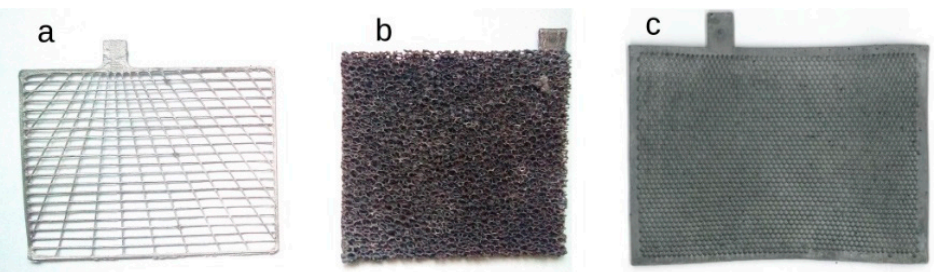

Figure 2. Typical (a), reticulated (b), and honeycomb (reprinted from [55] with permission from Elsevier) (c) current collectors for lead-acid batteries.

The capacitance of carbon materials not only plays an important role when the material is used as an additive to the negative mass, but they can also be used to replace a whole standard negative plate with a capacitor plate $[65,66]$. The capacitor plate uses the capacitance of the carbon material to store charge instead of using typical faradaic reactions in the active mass. Such a solution delivers more power and better charge acceptance but lowers the capacity of the battery. The capacitor plate can be used instead of the standard negative plate or in parallel with it. The former solution is used in Axion Power's Pb-C battery, whereas the latter is used in the Ultrabattery developed by the Australian Commonwealth Scientific and Industrial Research Organization. These hybrid batteries were characterized by improved power, lifespan, and high-rate charge acceptance $[3,66,67]$. The properties of the batteries with capacitor plates improve the prospects of using lead-acid batteries in electric and hybrid vehicles.

The use of carbon allowed drastic improvements of current batteries and helped them achieve their current, strong market position. At the same time, new technologies 
improving the construction of this type of battery are constantly being developed. The main technologies incorporating carbon were described above: additives to the active mass, reticulated current collectors, and capacitor electrodes. There are different forms of carbons being used in these applications with more advanced materials, e.g., composites or nanomaterials, leading to better tailored properties at an increased cost of manufacturing. Using carbon materials allows the continued use of lead-acid batteries as a cheaper and safer alternative to newer battery types. At the same time, lead-acid batteries can constantly improve their electrochemical parameters and achieve good performance. Their main drawback is currently their low specific energy compared to other battery types. Depending on charge/discharge conditions, their cycle life can also be restricted. Current research on the improvement of lead-acid batteries focuses in great part on increasing their capacity and extending their HRPSoC cyclability, while maintaining their low cost and efficient recycling. The total market value of lead-acid batteries is still growing, even in recent years, especially in developing countries [12]. They have good prospects for the near future, as they are an attractive option for the growing market of storage of energy produced from renewable sources.

\section{Lithium-Ion Batteries}

Lithium-ion batteries are one of the most widely used secondary batteries with a dynamically increasing market share. The worldwide market for lithium-ion batteries was over 55 billion USD in 2017 [12]. In Li-ion batteries, the positive electrode material is an intercalated lithium compound, e.g., $\mathrm{LiCoO}_{2}, \mathrm{LiMn}_{2} \mathrm{O}_{4}$, lithium nickel manganese cobalt oxides (NMC, layered compositions with different Co:Ni:Mn ratios), or $\mathrm{LiFePO}_{4}[15,68,69]$. Most commercial Li-ion batteries have carbon materials as a negative electrode. When a battery is charged, the lithium ion from the positive electrode get inserted into the negative electrode, while the opposite occurs during discharge. During discharge, the carbon material electrode works as an anode. The basic parameters determining the choice of the anode material are the lithium intercalation and de-intercalation reversibility, chemical, thermal, and electrochemical environment, electrical conductivity, cyclic stability, and cost. Due to its good electrical properties and long cycle life, graphite is the most commonly used anode material $[70,71]$. The stoichiometry of lithium bonding (one $\mathrm{Li}^{+}$can be intercalated per six $\mathrm{C}$ atoms - the limiting composition is $\mathrm{LiC}_{6}$ ) limits the theoretical specific capacity of graphite to around $370 \mathrm{mAh} / \mathrm{g}[70,72]$.

$$
\mathrm{Li}_{x} \mathrm{C}_{6} \leftrightarrow \mathrm{C}+\mathrm{xLi}^{+}+\mathrm{xe}^{-}
$$

Non-graphitic carbon materials are also used as the negative electrode material. These materials are characterized by the appearance of amorphous areas together with more crystalline ones. Non-graphitic carbons are broadly classified into soft carbons (graphitizable carbons, where crystallites are stacked in the same direction) and hard carbons (non-graphitizable carbons, where crystallites have disordered orientation) [68]. Schematics of the structure of selected carbon materials are presented in Figure 3.

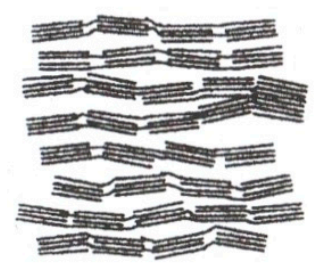

Soft carbon

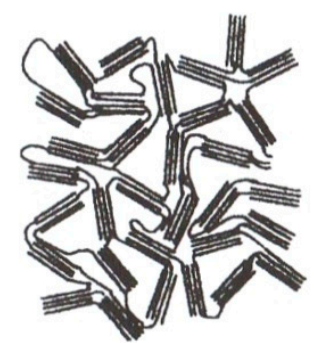

Hard Carbon

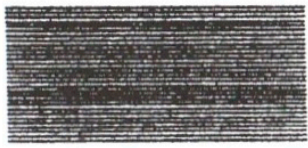

Graphite

Figure 3. Illustration of carbon types showing different stacking of the graphene layers. Reprinted from [68] with permission from Elsevier. 
The main advantages of soft carbons are long cycle life, coulombic efficiency over 90\%, and highly reversible specific capacity [70]. One of the first soft carbon materials applied in lithium-ion batteries was coke, which offered a capacity around $180 \mathrm{mAh} / \mathrm{g}$ and stability in the presence of propylene carbonate-based electrolytes. Currently, various carbon types are used in negative electrodes e.g., graphitic spheres and natural graphite [15,70,73]. Additionally, the improvement of cyclic stability of soft carbons can be achieved by modifying the surface of the carbon material, e.g., by a silane coating [74]. However, the specific capacity of these materials is similar to that of graphite. These properties result quite often in the use of soft carbons in small, low-power devices (portable electronics) but not in hybrid electric vehicles and electric vehicles.

The second group involves hard carbons. These materials offer higher capacity, typically around 500-1000 mAh/g [15,70]. The relatively high capacity of hard carbons compared to graphite can be explained by the fact that lithium in hard carbons additionally occupies the nearest neighbor sites between pairs of graphene sheets [75]. Another mechanism proposed is that lithium may also bind to the hydrogen-containing regions of carbon [76,77]. Hard carbons show a random alignment of graphene sheets and slow lithium diffusion inside the carbon structure. In turn, the disadvantages of hard carbons are its low initial coulombic efficiency and high loss in initial capacity. In connection with these problems, numerous works on hard carbons modification were carried out [78-83]. One of the proposed solutions is carbon surface modification by oxidation. It was observed that a mild oxidation of carbon leads to pore production, which is a crucial process in obtaining higher capacity [78]. Another solution is the application of a soft carbon layer on hard carbon. This modification resulted in a high-power performance and good cycling stability [79]. An improvement of the working parameters of negative electrodes based on hard carbons can also be achieved by using high-porosity carbons. Hu et al. [80] obtained and applied hard carbon spherules as a porous carbon material. A scanning electron microscope (SEM) image illustrating the morphology of such a material is presented in Figure 4. The proposed electrode showed an improvement of electrochemical performance and a capacity of almost $390 \mathrm{mAh} / \mathrm{g}$.

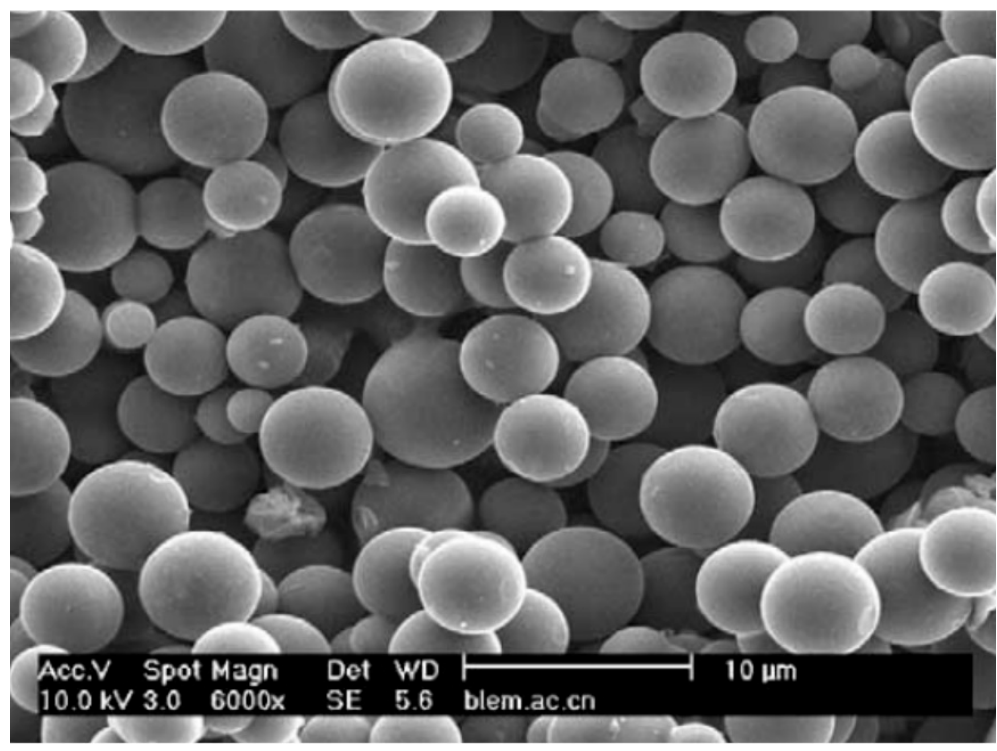

Figure 4. SEM image of hard carbon spherules. Reprinted from [80] with permission from Elsevier.

Similar capacity (344 mAh/g) was shown by the material obtained by Rao et al. [81]. Hard carbon in this study was prepared by calcination of polypropylene cyanide. The obtained material showed an initial coulombic efficiency over $87 \%$ and a superior cycle stability at different current rates compared to graphite. Li et al. [82] examined a microporous hard carbon prepared from potato starch. The electrochemical tests revealed a good cyclic 
life and high reversible capacity (around $530 \mathrm{mAh} / \mathrm{g}$ ). Similarly, nanoporous hard carbon obtained from pyrolyzed sucrose exhibited a specific capacity close to $500 \mathrm{mAh} / \mathrm{g}$ (at $0.2 \mathrm{C}$ rate) and an equally good capacity, around $330 \mathrm{mAh} / \mathrm{g}$ at $5 \mathrm{C}$ rate [83].

Hard carbons in general are characterized by a faster decrease in capacity compared to soft carbons but higher specific capacity (above $500 \mathrm{mAh} / \mathrm{g}$ ), especially in the case of highly porous materials. At the same time, the price of hard carbons is only about $20 \%$ higher than soft carbons. Nevertheless, due to their high energy and power density, they are widely used in batteries in hybrid-electric and electric vehicles.

Recently, carbon nanomaterials (such as carbon nanotubes, nanofibers, and graphene) have become very promising candidates for use as anodes in lithium-ion batteries. Compared to other materials, carbons nanomaterials have a higher specific theoretical capacity, e.g., $1116 \mathrm{mAh} / \mathrm{g}$ for single-walled nanotubes in $\mathrm{LiC}_{2}$ stoichiometry [84-86]. Nanomaterials also offer other advantages, such as stable cyclic behavior and increased lithium ions diffusion rate. The use of carbon nanotube composites with other carbon materials allowed for the improvement of many parameters, such as electrical conductivity, transport properties, and thermal and mechanical stability. On the other hand, the basic disadvantages of nanosized particles are high surface reactivity, low coulombic efficiency during the first cycle, tendency to aggregation during cycling, and higher price [72,87]. Moreover, in practice, it is difficult to achieve the theoretical capacity, and the properties of carbon nanomaterials depend on the preparation methods and pretreatments (e.g., ball milling, acid treatment) [85]. Various morphological modifications of the nanotubes are known, which allow them to reach a capacity of approximately $1000 \mathrm{mAh} / \mathrm{g}[88,89]$. Appropriate modification of parameters such as the tube diameter, wall thickness, or porosity allows improving the working parameters of such anode materials. Even the shape of the nanotubes can be changed. Bamboo-shaped carbon nanotubes produced by using a cresol precursor are characterized by an improved cycle stability and electric conductivity [88]. Quadrangular carbon nanotubes have a high specific capacity and good high-rate performance [89]. High reversible capacity was also found in the case of chemically nano-drilled multiwalled carbon nanotubes [90]. The structures of such materials are presented in Figures 5 and 6.

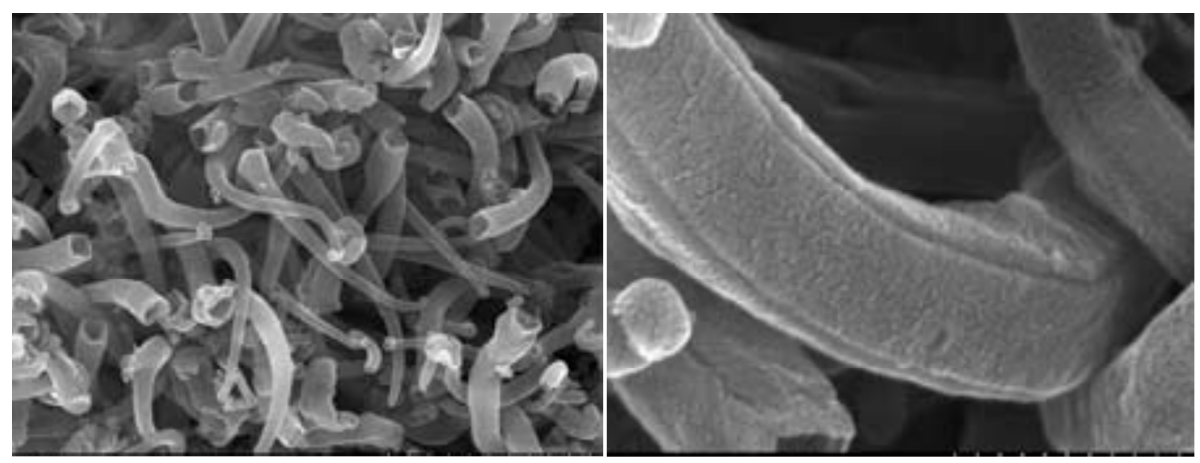

Figure 5. SEM images showing morphology of quadrangular carbon nanotubes. Republished with permission from the Royal Society of Chemistry, from [89]; permission conveyed through Copyright Clearance Center, Inc. (Danvers, MA, USA). 


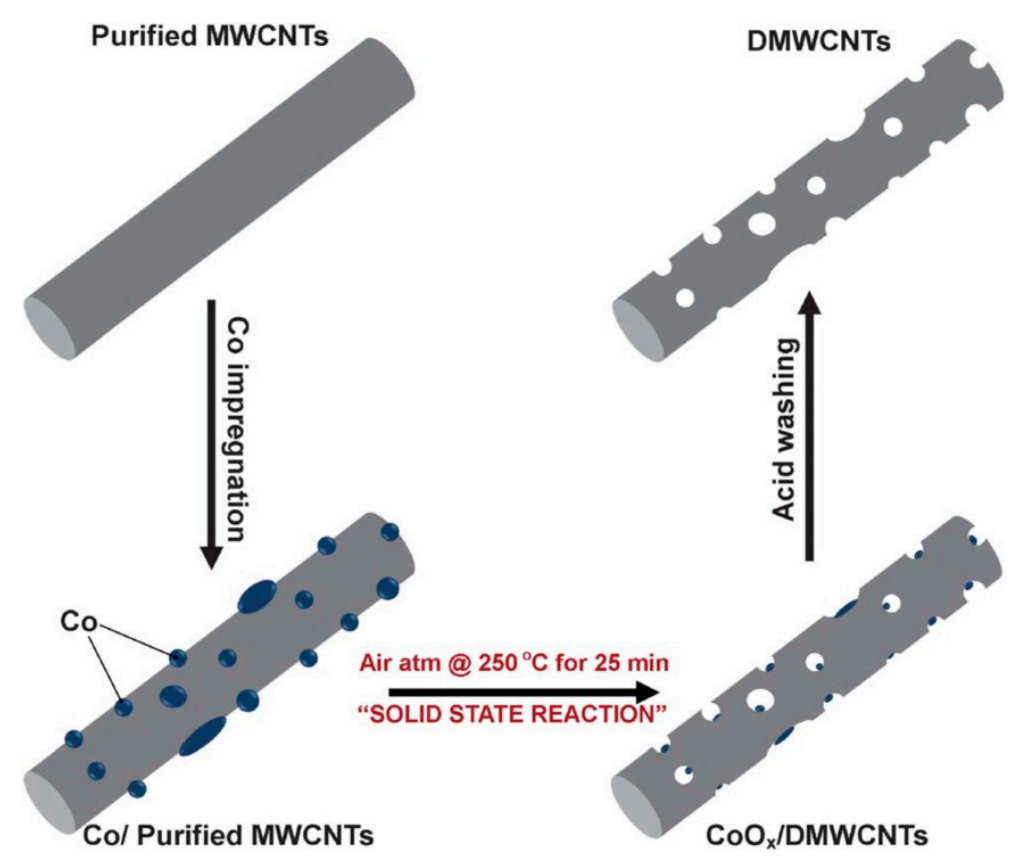

Figure 6. Schematic structure and procedure of preparing drilled multiwalled carbon nanotubes (DMWCNTs) from multiwalled carbon nanotubes (MWCNTs) Republished with permission from the Royal Society of Chemistry, from [90]; permission conveyed through Copyright Clearance Center, Inc. (Danvers, MA, USA).

A considerable number of studies investigated composites of carbon nanomaterials (nanotubes, nanofibers) with semi-metals, metals, and metal oxides such as $\mathrm{Si}, \mathrm{Ti}, \mathrm{TiO}$, $\mathrm{MnO}, \mathrm{Fe}, \mathrm{Fe}_{2} \mathrm{O}_{3}, \mathrm{Fe}_{3} \mathrm{O}_{4}, \mathrm{Co}, \mathrm{Ni}, \mathrm{Cu}, \mathrm{Ge}, \mathrm{Nb}_{2} \mathrm{O}_{7}, \mathrm{Sn}, \mathrm{SnSb}$, and $\mathrm{SnO}_{2}$ [91-99]. The use of composite material allows for the improvement of many parameters. It has been found that the use of a nickel and titanium contact in a free-standing single-walled carbon nanotube electrode increased both the reversible lithium ion capacity and the rate capacity [92]. Another example is the $\mathrm{Fe}_{3} \mathrm{O}_{4}$-carbon nanotube composite presented by Wu et al. [95], which exhibited a high reversible capacity, high rate capability and remarkable capacity retention. Graphene is yet another material of interest for use as the anode material in lithium-ion batteries with a specific capacity at the level of 780-1120 mAh/g, depending on its structure [100-102]. Anode materials based on graphene sheets exhibit a high specific capacity (around $1000 \mathrm{mAh} / \mathrm{g}$ ) and long cycling capability, up to 3000 cycles [100,103,104]. Graphene composite materials are also known to be used as anodes. Good anode properties, highly reversible capacity, and small loss from initial capacity were exhibited by graphene composites with silicon [93], $\mathrm{SnO}$ [105], or $\mathrm{Fe}_{3} \mathrm{O}_{4}$ [106]. Figure 7 illustrates how the introduction of nanomaterials and composite materials can lead to marked improvements in characteristics of the anode.

In recent years, lithium titanate with a spinel structure (LTO) has been studied as a potential anode material characterized by a good cycling stability $[107,108]$. Over the last 10 years, there has been a continuous increase in the number of studies from about 50 publications per year in 2010 to almost 300 in 2020 [13]. Carbon materials are also used as additives to LTO anodes. Carbon nanotubes and graphene used as additives provide good contact between particles and conductivity at the interfaces [109-111]. Additional solutions for improving electrochemical properties and capacity retention are carbon additives with a large surface area such as carbon black, mesoporous carbon, and amorphous carbon [112-114]. 


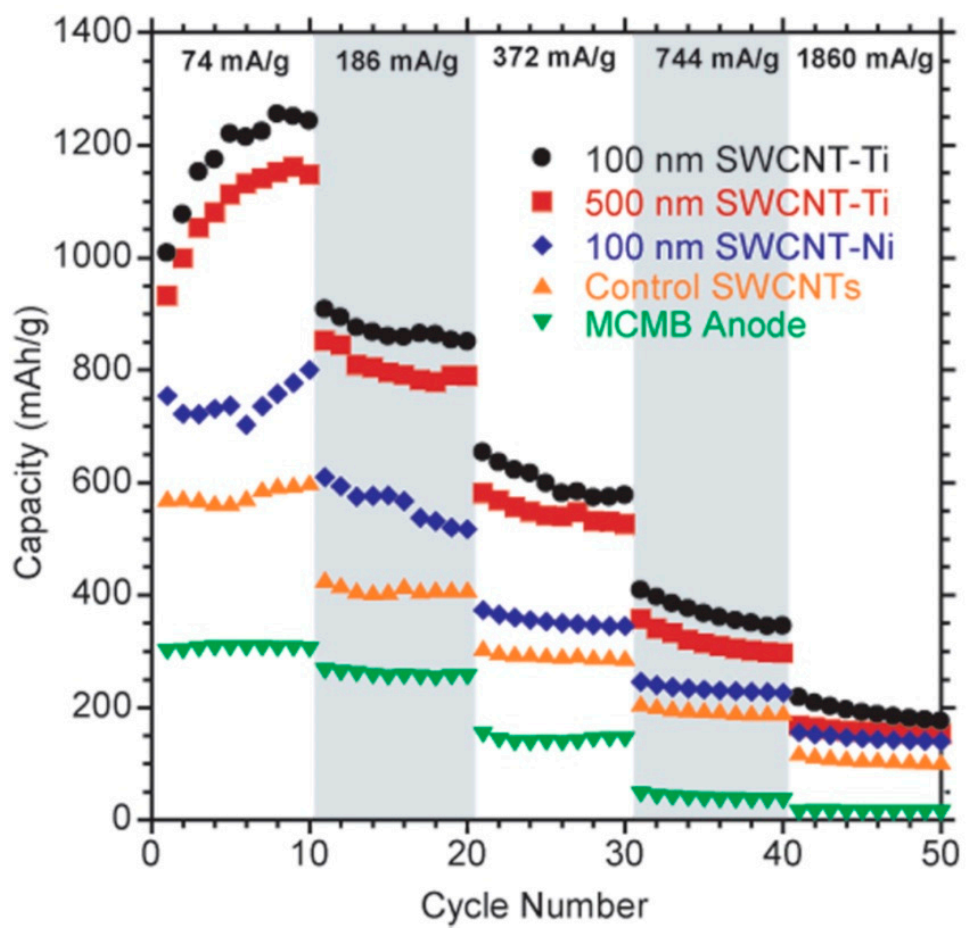

Figure 7. Rate cycle performance of various electrodes: single-walled nanotubes (SWCNT) (orange), SWCNT composite with Ni (blue), SWCNT composite with Ti (100 nm nanotube size-black; $500 \mathrm{nm-}$ red), and standard graphite mesocarbon microbead (MCMB) (green). Reprinted with permission from [92]. Copyright 2010 American Chemical Society.

Another new research area involves lithium-ion capacitors, a combination of a a faradaic lithium-ion battery anode and a supercapacitor cathode, which offers rapid charging-discharging capability and long cycle life. In this promising technology, carbon materials can be used in both the positive and the negative electrode [115-117]. Lithium-ion capacitors combine high energy density with high power density and excellent durability. Due to this, an important potential application for lithium-ion capacitors is represented by energy recovery systems in industrial machinery and transportation systems. Hybrid ion capacitors can be successfully used in regenerative braking energy harvesting from trains, heavy automobiles, and ultimately electric and hybrid-electric vehicles.

The carbon materials used during the earlier phases of lithium-ion battery development were mainly graphite and soft and hard carbons. With maturing of the technology and the introduction of new available techniques and concepts, other carbon materials were employed. In particular, the use of carbon nanomaterials is very promising. They can lead to large improvements of the capacity and the cycle life of lithium-ion batteries. Their successful and economically viable introduction into mass-produced battery models would provide lithium-ion batteries with a very dominant position in the current market. Some of the disadvantages of currently used lithium-ion batteries are their temperature limitations, limited safety, and comparatively high cost. To address these problems, many potential solutions are being researched, including technologies beyond the scope of this review, e.g., solid-state electrolytes or new electrode compositions. The recent growth of portable electronic devices and electric vehicles creates a very attractive market for lithium-ion batteries with proper characteristics and provides strong incentives for developing further improvements in these batteries.

\section{Lithium-Sulfur Batteries}

Lithium-sulfur batteries are a promising technology which can replace contemporary lithium-ion batteries. The general concept of Li-S batteries is presented in Figure 8. They are characterized by an impressive theoretical capacity, equal to $1672 \mathrm{mAh} / \mathrm{g}$ for the sulfur 
electrode and $3861 \mathrm{mAh} / \mathrm{g}$ for the lithium electrode [118-120]. Additionally, the cost of their production is low, as the elements used in their construction, including sulfur, are more abundant than transition metals or rare earth elements required for modern lithium-ion batteries [121-124].

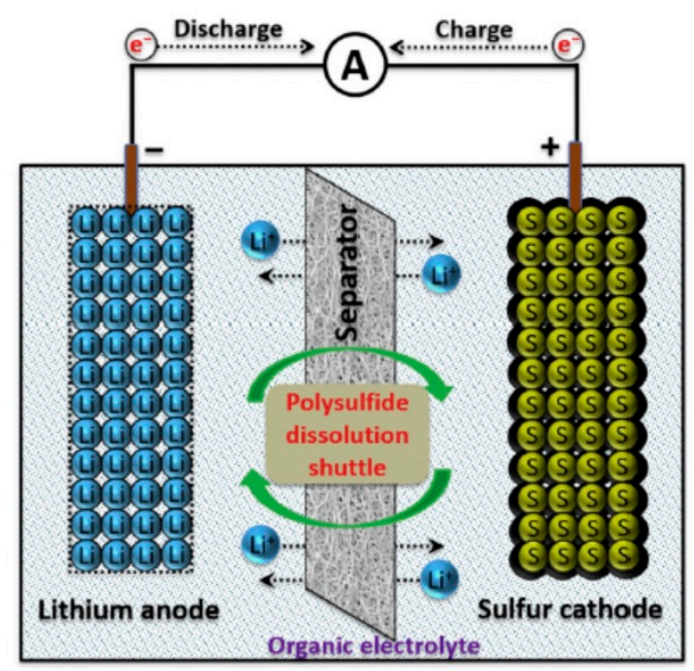

Figure 8. Schematic representation of an Li-S battery. Reprinted from [120] with permission from Elsevier.

On the other hand, current Li-S batteries have some drawbacks [119,120,125-127]. The sulfur electrode has relatively low utilization of the active material. Additionally, sulfur has low electric conductance and poor high-rate current performance. The density of $\mathrm{Li}_{2} \mathrm{~S}$ is about $20 \%$ lower than that of sulfur $\left(1.66 \mathrm{~g} / \mathrm{cm}^{3}\right.$ vs. $2.03 \mathrm{~g} / \mathrm{cm}^{3}$, respectively [128]), which leads to changes in the volume of the material during cycling of the sulfur electrode, thereby decreasing the stability and cycle life. Another problem is the so-called shuttle effect. High-order polysulfides are soluble in electrolytes typically used in Li-S batteries and can migrate to the anode and discharge there, which leads to low efficiency and poor cyclic stability. Lastly, because of use of metallic lithium in anodes, Li-S batteries are susceptible to the creation of dendrites, which can increase the self-discharge the battery and create potentially dangerous short-circuits.

There have been many new technologies in Li-S batteries introduced in recent years to alleviate these problems (e.g., protecting the lithium metal anode surface or using nonlithium anodes, changes in electrolyte composition, and modifications of the separator to block the diffusion of lithium) $[125,129]$. One of the most popular modifications is the application of carbon in the cathode. Sulfur can be embedded in carbon materials, and appropriate adsorbents for trapping lithium polysulfides can be utilized. Sulfur can be integrated into the carbon microstructure via physical or chemical methods $[120,122,130]$. The former includes encapsulation and infiltration of sulfur into the carbon material, while the latter involves the creation of bonds between $C$ and $S$ atoms, e.g., via surface functionalization or chemical reaction deposition. Using the described methods to restrict sulfur species to a carbon matrix, while allowing an effective diffusion of lithium, leads to improvements in the electrochemical characteristics of cathode. Materials such as acetylene black, graphene, carbon nanotubes, nanofibers, porous carbon, fullerenes, and hollow materials, e.g., nanospheres, were utilized in this manner in various studies [119,120,131-134].

When using porous carbon in Li-S batteries, one of the important aspects is the size of its pores. Nanopores have a high surface area and can block the electrolyte molecules from entering and dissolving lithium polysulfides, improving their immobilization. On the other hand, mesoporous materials allow for higher loading of sulfur into the material and better mitigation of stress during expansion of sulfur material, while they are additionally 
characterized by a better electric conductivity and superior structure properties, and they can be used to prepare electrodes with low thickness $[121,129,135,136]$.

Another carbon material used for the immobilization of sulfur is graphene. It has very good conductance and flexibility but has limited ability to alleviate the shuttle phenomenon. However, this phenomenon can be more readily overcome by using graphene oxide or partially oxygenated graphene $[129,137,138]$.

Carbon nanomaterials, e.g., nanotubes, are also a very interesting materials when used in cathodes, owing to their stability, excellent mechanical properties, and conductivity $[129,139-143]$. Further improvements can be achieved by doping, e.g., N doping leads to improved charge transport and electrolyte access. Creating hierarchical structures also leads to improvements in the properties of the material when used as a cathode in Li-S batteries, such as its porosity and electrolyte permeability [144]. Carbon nanotubes can also be used to modify the separator, improve the sulfur utilization, and inhibit the diffusion of lithium polysulfides $[129,145]$. Due to their unique structure, carbon nanofibers are also a material that can be used in cathodes, allowing sulfur to be stored inside them, as shown schematically in Figure 9. When modified by surface activation or combined in composite materials, nanofibers were also successfully used as cathode materials [129,146-149].

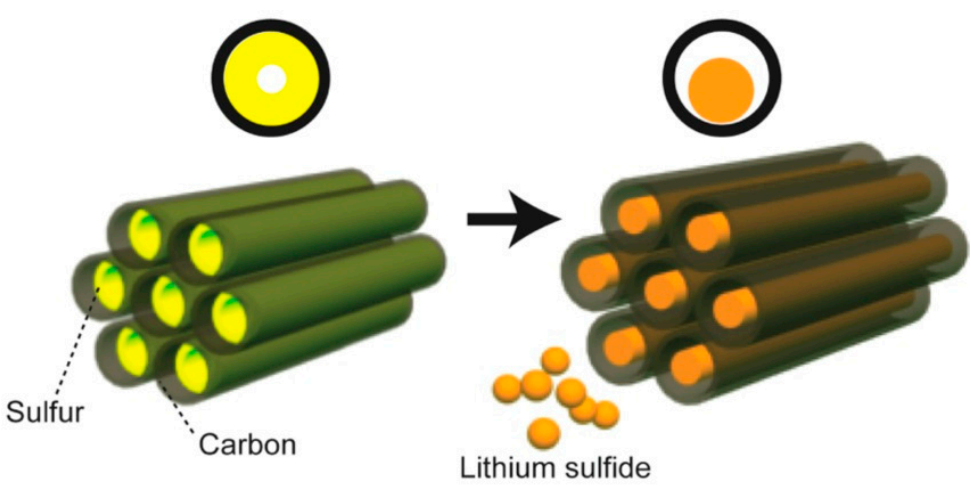

Figure 9. Changes in the morphology of nanotube-based sulfur cathode during discharge. Reprinted with permission from [149]. Copyright 2013 American Chemical Society.

There have been recent interesting developments regarding the source of the carbon for the cathode materials in Li-S batteries. They can be obtained from biomaterials, further decreasing the impact of this technology on the environment. For example, there have been studies of nanofibers generated from bamboo material applied in Li-S batteries [150]. Porous carbon can be based on cinnamon [125], waterweed [151], or silk cocoons [127,152].

The various carbon materials described in this section have their own advantages and disadvantages. Selection of the appropriate material will be largely dependent on the exact application of the battery. Parameters such as the anticipated working conditions, construction and scale of the battery, cost, and availability of synthesis methods need to be considered.

There is also a whole family of composite carbon materials used in Li-S batteries. Composites of graphene with various oxides have a much-improved ability to retain sulfur species in their structure compared to graphene. Oxides such as $\mathrm{Co}_{3} \mathrm{O}_{4}, \mathrm{SiO}_{2}$, and $\mathrm{TiO}_{2}$ can be employed in such materials [153-155]. Porous carbon can also be used in composite materials instead of graphene, e.g., together with $\mathrm{B}_{2} \mathrm{O}_{3}, \mathrm{Nb}_{2} \mathrm{O}_{5}$ [156,157], or atomic Co $[158,159]$. Carbon nanotubes can also be employed in this role. Using carbon nanotube composites with, e.g., $\mathrm{MgO}, \mathrm{MnO}_{2}, \mathrm{SnO}, \mathrm{TiO}_{2}$, or Co-based nanoboxes improves the cyclability and sulfur retention inside such materials [119,160-162]. Composites of carbon nanospheres with metal oxides (e.g., $\mathrm{Fe}_{3} \mathrm{O}_{4}, \mathrm{MnO}_{2}$, and $\mathrm{TiO}_{2}$ ) also display behavior similar to composites with carbon nanotubes, including improvements when using $\mathrm{N}$-doped nanospheres [163-165]. The composite materials often have improved properties compared to their components; however, their preparation can be a complex and multistage process. 
An example of such a process, along with a schematic representation of the structure of the obtained material, is shown in Figure 10. As indicated earlier, doping carbon with heteroatoms such as nitrogen leads to improvements in polysulfide retention in carbon materials. Such doping is a less expensive and more environmentally friendly option than using metal oxides $[22,166]$.

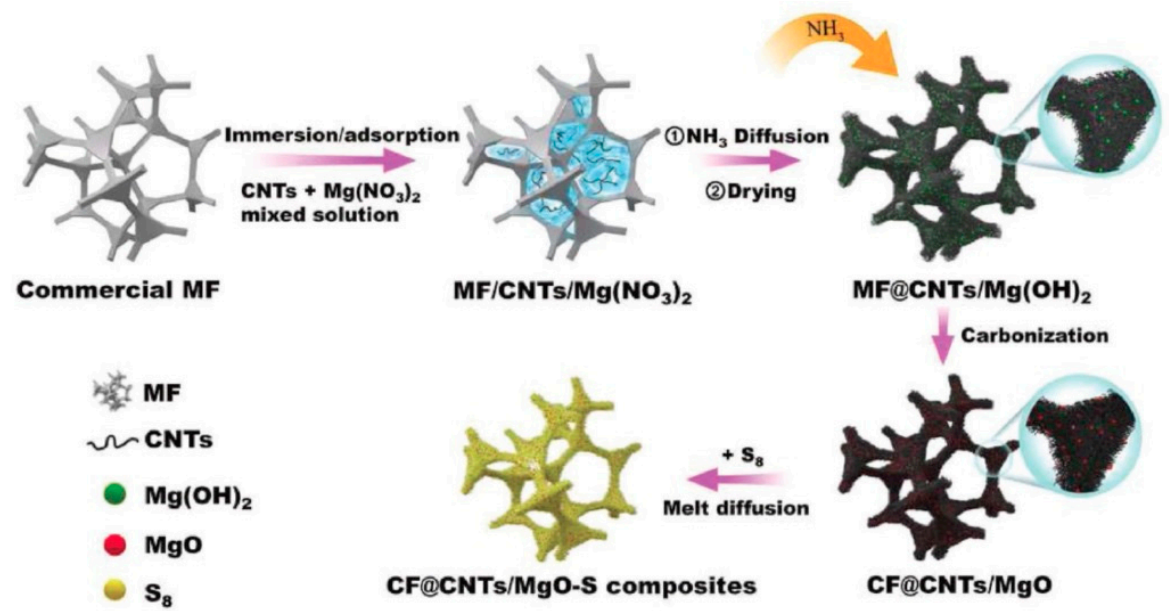

Figure 10. Preparation of a MgO/carbon nanotube/carbon foam composite material. MF-melamine foam, CF—carbon foam, CNTs—carbon nanotubes. Reprinted from [160] with permission from John Wiley and Sons.

Metal-organic frameworks (MOFs) are one of the topics of considerable interest at present, and they can also be used as part of the composite material for an Li-S battery cathode. Carbon can be introduced into composite MOF materials, and such solutions usually outperform either component, as well as improve the cycle life and suppress dendrite formation [22,167-169].

Currently, the majority of focus in Li-S battery research lies on cathodes; however, there have also been some studies regarding anodes, including the use of carbon materials in them $[22,129]$. Typical metallic anodes made of lithium are prone to dendrite creation, leading to short-circuits and self-discharge of the Li-S battery. To mitigate this problem different carbon materials can be used. Carbon materials can facilitate the generation of a stable, protective layer in the solid electrolyte interface [143]. The addition of graphitic carbons results in a construction more similar to lithium-ion batteries, where lithium is intercalated in the anode. On the other hand, in contrast to lithium-ion batteries, many exfoliation-preventing solvents cannot be used in $\mathrm{Li}-\mathrm{S}$ batteries due to their reactivity with sulfur species generated in these batteries [170]. In addition to graphitic carbons, hard carbons, graphene, and composite materials with lithium have been studied as materials used in the construction of anodes $[118,120,171]$. Carbon materials used in these anodes generally improve the safety and stability of the battery, but they can lead to a decrease in capacity and slower reaction kinetics.

Li-S battery technology is very closely related to carbon materials and has good prospects for the near future, considering its potential for very high capacities and energy densities. The use of carbon materials has allowed greatly mitigating the initial difficulties with the limited stability, shuttling effect, and high self-discharge. Implementation of improved $\mathrm{Li}-\mathrm{S}$ batteries in electric vehicles could greatly extend their effective range. However, there currently remain problems in the mentioned areas that need to be solved before commercialization, although new generations of carbon materials used as electrode materials offer promising solutions. In particular, the use of nanomaterials and composites can result in materials with very good properties, increasing the loading of sulfur and its effective trapping. Application of these materials can lead to successful implementation of Li-S technology. On the other hand, these batteries are very complex, and changes in one parameter can influence the behavior of the whole system; thus, research on electrode 
materials has to progress in parallel to work on other battery elements, such as binders, electrolytes, or separators.

\section{Sodium-Ion Batteries}

Sodium-ion batteries are also regarded as a potential alternative to lithium-ion batteries. The principle of operation of sodium-ion batteries is the same as that of $\mathrm{Li}$-ion batteries, with the difference being the charge carrier, i.e., sodium ions $\left(\mathrm{Na}^{+}\right)$. The principle of sodium-ion battery operation is shown in Figure 11.

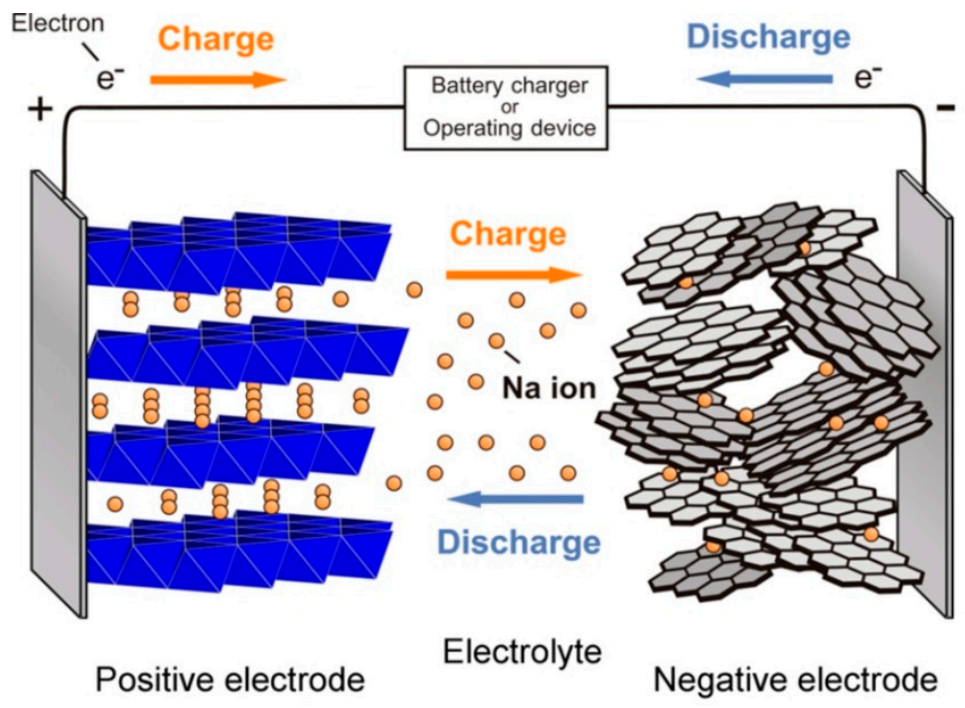

Figure 11. Schematic illustration of sodium-ion batteries. Reprinted with permission from [172]. Copyright 2014 American Chemical Society.

Because of the higher ionic radius for sodium $(0.102 \mathrm{~nm})$ than lithium $(0.076 \mathrm{~nm})$, larger interstitial sites for Na-ion intercalation are required [172-174]. Minimal amounts of sodium ions may be intercalated into graphite- one of the most popular anode materials in lithium-ion batteries. Due to this, various other carbonate materials such as hard carbons, graphene, and graphene-based composites have been considered as the anode material for sodium-ion batteries [175,176]. The main advantages of these carbon materials are conductivity, corrosion resistance, high surface area, and low cost. At the same time, the morphology of carbon materials has a great influence on their properties.

One of the solutions used in sodium-ion batteries is the application of hard carbons. There have been many studies of the use of hard carbons from organic materials and wastes such as sugar [177], banana peels [178], okara [179], waste tire [180], peanut skin [181], grass [182], cellulose [183,184], rise husk [185], coffee [186], wood [187], and lignite [188]. This group of materials is characterized by a good cyclic stability and specific capacity at the level of 200-400 mAh/g. There have also been studies on the application of soft carbon as the anode material. Luo et al. [189] demonstrated that soft carbon can be a competitor to hard carbon if the preparation conditions are optimal. It has been shown that this material has a high cyclic resistance due to highly reversible lattice expansion. Hard carbons are very promising candidates for anode materials with high capacities, but they have highly irreversible capacities. This high irreversibility was reported to depend on particle size, porosity measurements, applied additives, and electrolytes. Due to the large size of the Na ions, anode materials based on soft carbons showed lower specific capacities. Only when the preparation conditions are carefully chosen can soft carbon become a high-rate anode material.

Another proposed solution involves porous carbon nanomaterials. Nanocellular carbon foams exhibit a good capacity retention (around $150 \mathrm{mAh} / \mathrm{g}$ after 1600 cycles at $0.1 \mathrm{~A} / \mathrm{g}$ ) due to their large surface area and the surface functional groups available for 
sodium-ion insertion [190]. An equally high performance was shown by porous carbon nanofibers (high cyclic durability and capacity around $140 \mathrm{mAh} / \mathrm{g}$ after 1000 cycles at $0.5 \mathrm{~A} / \mathrm{g}$ ) [191] or three-dimensional amorphous carbon (rate capability $66 \mathrm{mAh} / \mathrm{g}$ at $9.6 \mathrm{~A} / \mathrm{g}$ ) [192]. An improvement of working parameters was also obtained by doping the porous carbon materials with heteroatoms such as nitrogen and oxygen [193-196]. Zhang et al. [196] presented a nitrogen-doped three-dimensional porous carbon anode material which exhibited a specific capacity around $270 \mathrm{mAh} / \mathrm{g}$, excellent cyclic stability, and capacity retention (approximately 91\% after 5000 cycles at $1 \mathrm{~A} / \mathrm{g}$ ).

Reduced graphene oxide (RGO) is another promising material for use in sodium-ion batteries due to its superior sodium-ion storage properties. It was shown that RGO with an interlayer spacing of $0.37 \mathrm{~nm}$ could deliver a capacity of $174 \mathrm{mAh} / \mathrm{g}$ (at $0.04 \mathrm{~A} / \mathrm{g}$ ) [197]. Moreover, expanding the interlayer spacing to $0.43 \mathrm{~nm}$ increased the capacity to $280 \mathrm{mAh} / \mathrm{g}$ at a current of $0.02 \mathrm{~A} / \mathrm{g}$ [198]. RGO properties are strongly dependent on the structure and method of preparation. In mass production, RGO is prepared from graphite. The first step is the chemical exfoliation of graphite to graphene oxide, and then the oxide is reduced with chemical agents, such as sodium borohydride [199], potassium carbonate [200], tin chloride [201], or iron metal powder [202]. The metal-reduced graphene obtained by Kumar et al. [203] showed good properties as a negative electrode material in sodium-ion batteries. The tested anode exhibited a specific capacity of approximately $270 \mathrm{mAh} / \mathrm{g}$, good cyclic stability, and a superior rate capability. Figure 12 illustrates the poor capacity of graphite as an anode material in Na-ion batteries and the marked improvements that can be achieved by applying other carbon materials.
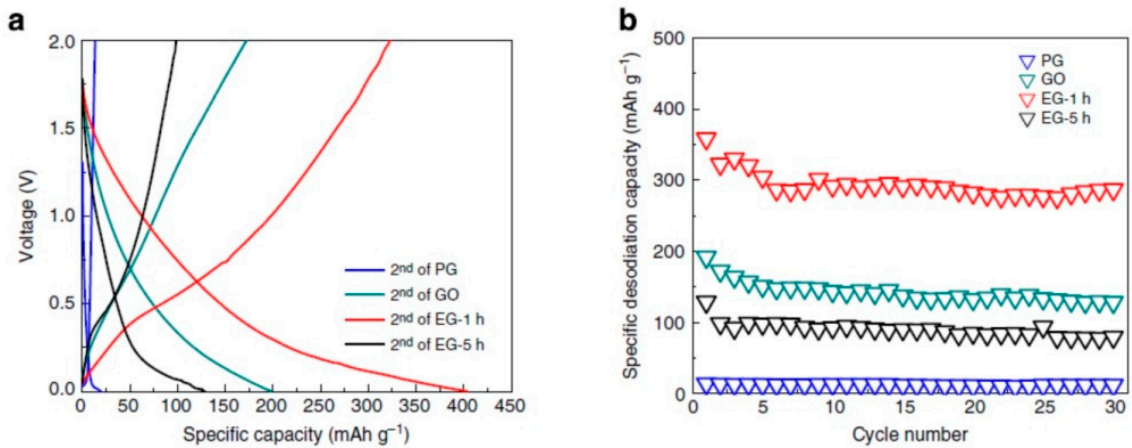

Figure 12. Electrochemical performances of graphite (PG), graphene oxide (GO), and expanded graphite (EG) anodes in sodium-ion batteries: (a) charge/discharge curves for the second cycles; (b) short-term cycling stability. Reprinted with permission from the Springer Nature Customer Service Center $\mathrm{GmbH}$ [198].

The use of carbon composites as a negative electrode material is an interesting solution that combines the advantages of metal alloys and carbon materials $[175,204]$. Some alloy material elements $(\mathrm{Ge}, \mathrm{Se}, \mathrm{Sn}$, and $\mathrm{Sb}$ ) deliver appropriate Na-inserting potential and high theoretical specific capacities (over $600 \mathrm{mAh} / \mathrm{g}$ ) [205-207]. At the same time, carbon additives improve the electrical conductivity, as well as chemical and mechanical stability, of the electrode material, and prevent agglomeration during cycling [175]. Recently, many studies investigated anode materials based on Ti [208,209], Sn [210], Sb [211,212], and P $[89,213,214]$. Carbon nanotube composites with $\mathrm{Sn}$ and/or Sb films featured excellent conductivity, while the modification yielded a capacity of around 600-800 mAh/g and good cyclic stability $[210,212,215]$. Another example involves $\mathrm{TiO}_{2}$ nanoparticles grown on $\mathrm{N}$-doped graphene, which exhibited a reversible capacity of approximately $400 \mathrm{mAh} / \mathrm{g}$ / (at $50 \mathrm{~mA} / \mathrm{g}$ ) and $250 \mathrm{mAh} / \mathrm{g}$ after 100 cycles [216]. Phosphorus compositing is an effective way to develop high-performance anodes for long cycle life by minimizing drawbacks such as low electrical conductivity and large volume expansion during cycling. The phosphorus-graphite-polyaniline composite anode material presented by Jin et al. [217] showed excellent capacity retention of $520 \mathrm{mAh} / \mathrm{g}$ after 1000 cycles at a high current 
density of $4 \mathrm{~A} / \mathrm{g}$. Carbon composites allow improving ionic and electronic transfers, which in turn facilitates better performance with high capacity and stable cycling properties.

Sodium-ion batteries are a promising alternative to lithium-ion batteries. The major advantages of sodium-ion batteries are better sustainability and low cost (about 10-20\% less than that of lithium-ion batteries) while maintaining a comparable specific energy. The natural abundance of $\mathrm{Na}$ and the possibility of using cathode materials based on metals such as $\mathrm{Fe}, \mathrm{Mg}, \mathrm{V}$, and $\mathrm{Ti}$, without using $\mathrm{Co}$, make the sodium-ion battery concept economically competitive and environmentally friendly. This battery may find application in short-range electric vehicles and large-scale energy storage systems. Nevertheless, the technology of sodium-ion batteries still needs to be refined, especially in terms of higherspecific-capacity electrode materials, as well as in other aspects such as the development of electrolytes that will improve the performance at high charge-discharge rates over a wide temperature range while exhibiting a long cycle life.

\section{Supercapacitors}

In contrast to standard capacitors based on dielectrics, supercapacitors store charge using electric double-layer capacitance or pseudocapacitance, i.e., electrochemical Faradaic reactions of adsorbed ions [218,219]. A comparison of charge storage mechanisms in different electrochemical power sources is shown in Figure 13. The former mechanism is used in capacitors based on carbon materials with high specific surface areas, whereas the latter is used in metal-oxide supercapacitors, based on compounds such as $\mathrm{RuO}_{2}$ or $\mathrm{MnO}_{2}$. Carbon in various forms finds use in both types of supercapacitors, as well as in hybrid capacitors, using composite materials combining carbon and metal oxides [220,221]. Supercapacitors are characterized by a very high specific capacitance; they also display good specific power, high-rate charge and discharge, and a long cycle life. On the other hand, one of their main disadvantages is a relatively low energy density $[218,220,222]$.

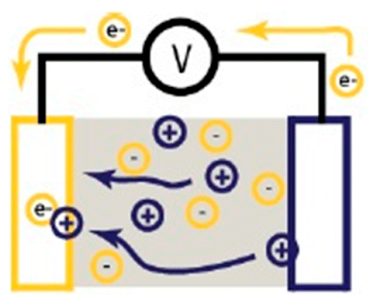

battery

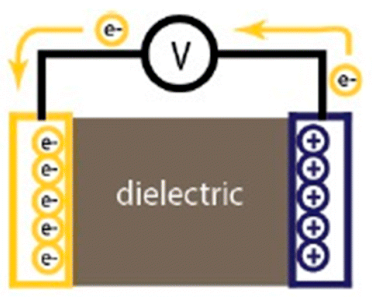

capacitor

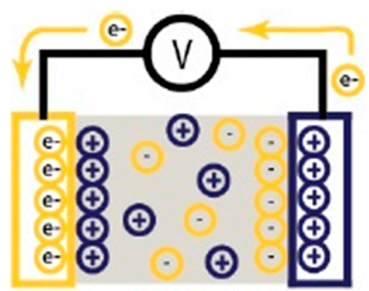

supercapacitor

Figure 13. Schematics showing the differences in charge storage in a battery, a capacitor, and a supercapacitor. Reprinted with permission from the Springer Nature Customer Service Center $\mathrm{GmbH}$ [223].

Modern electrochemical double-layer capacitors (EDLCs) often employ carbon materials with high specific surface area, such as activated carbon. Other important characteristics of materials used in supercapacitors are the chemical and physical stability, electrical conductivity of the material, and pore size. Greater porosity increases the surface area, but a balance in pore sizes is required as only macro- and mesopores facilitate rapid ion transfer [224-226].

There is a great interest in research on using different carbon materials in EDLCs, including carbon nanomaterials, which are usually characterized by a very high specific surface area, good mechanical strength, flexibility, and electrical conductivity $[220,227,228]$. On the other hand, nanomaterials have low volumetric capacity and can be difficult to produce $[223,229]$. Some of the carbon nanomaterials investigated to date are aerogels, nanotubes, graphene, and graphene oxide [229-234]. Advantages of carbon aerogels include the lack of the need for a bonding agent, as the aerogel can chemically bond to the collector with high capacitance $[220,231]$. Graphene electrodes based on graphite oxide have average capacitance, but high stability and high-rate current performance $[220,235]$. Carbon nanotubes used in supercapacitors have good physical properties, stability, and 
conductance $[220,229]$. There have also been studies on spherical, multiwalled onion-like carbons, which showed good performance as supercapacitor materials [229,236]. Microscopic images of some carbon nanomaterials used in supercapacitors are presented in Figure 14.
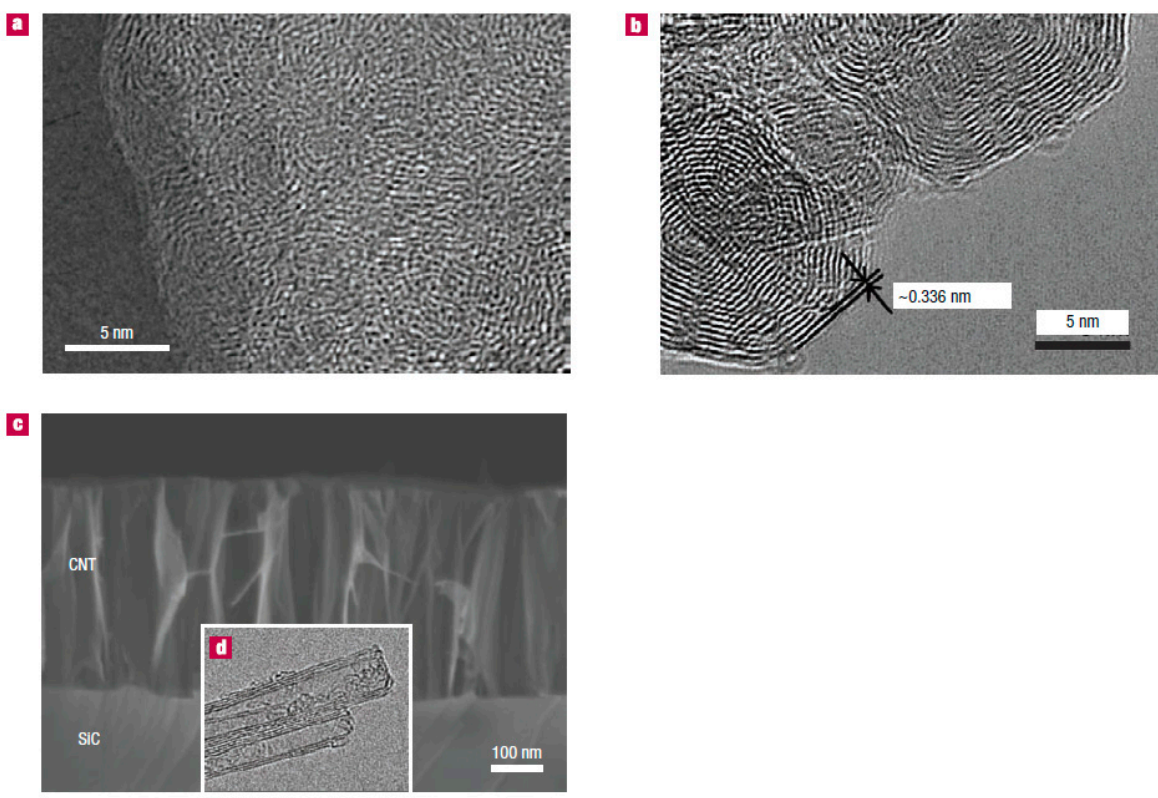

Figure 14. Transmission electron microscope images of different carbon structures used as active materials for double-layer capacitors: (a) disordered microporous carbon; (b) onion-like carbon; (c) SEM image of carbon nanotubes on $\mathrm{SiC} ;(\mathbf{d})$ carbon nanotubes. Adapted with permission from the Springer Nature Customer Service Center GmbH [237].

Some composite carbon materials have also been considered for use in EDLC. Examples include carbon quantum dots (with dimensions less than $10 \mathrm{~nm}$ ) that can be prepared on matrices of a three-dimensional aerogel or activated carbon. They can also create graphene- or carbon nanotube-quantum dot arrays [238-242]. An example of the structure of a material based on carbon quantum dots is presented in Figure 15. Nanotubes and activated carbon can also be used in composite materials to increase their capacitance. This is a better solution than simply mixing these two materials, as it allows for a more uniform embedding, thereby improving the mesoporosity [229]. Research on growing carbon nanotubes on top of carbon nanofibers resulted in a material with very good capacitance [243]. There have also been studies on modified graphene sheets. Chen et al. showed that reduced graphene oxide can be composited with active carbon [244]. Graphene can also be arranged in a hierarchic porous architecture, allowing for more efficient diffusion, as well as higher conductivity and capacitance $[208,245,246]$.

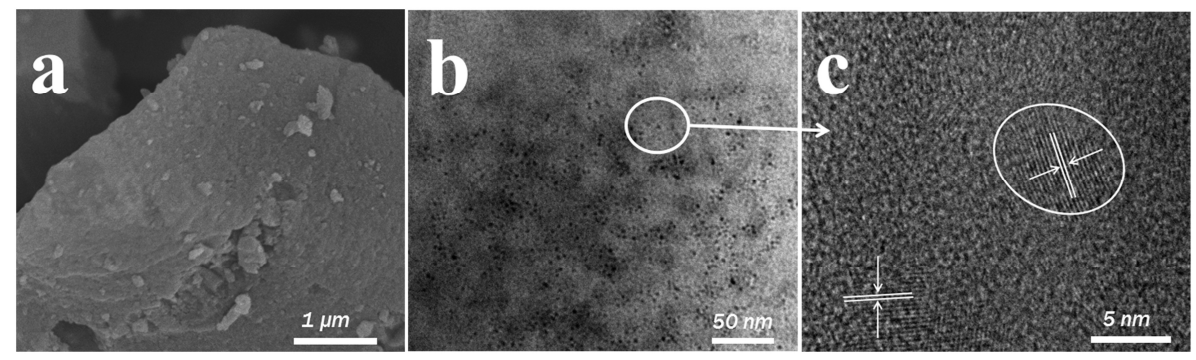

Figure 15. Microscopic images of an activated carbon/carbon quantum dot composite material: (a) SEM image of activated carbon; $(\mathbf{b}, \mathbf{c})$ high-resolution transmission electron microscope images of quantum dots. Reprinted from [242] with permission from Elsevier. 
Composite carbon materials can also include heteroatoms in their structure. Introducing these heteroatoms into the lattice changes not only the physical and chemical properties, but also the crystalline and electronic structure. $\mathrm{N}$ doping of carbon can lead to many improvements in material characteristics, such as capacitance and higher possible load currents [227,229,247,248].

Carbon materials can also find use in pseudocapacitance-based supercapacitors. This type of capacitor has a higher capacitance than EDLCs; however, in contrast to carbonbased supercapacitors, it has worse stability and high-rate performance. Addition of appropriate carbon materials can, therefore, lead to improved characteristics of composite pseudocapacitors by including electrical double-layer capacitance and providing a conductive backbone. For example, $\mathrm{MnO}_{2}$ supercapacitors with composite materials containing carbon black, graphene, or carbon nanotubes showed a marked improvement in their performance [249-251]. Carbon nanofibers were also used in a flexible, asymmetric capacitor with metal oxides $\left(\mathrm{MnO}_{2}\right.$ and $\left.\mathrm{MoO}_{3}\right)$ [252]. Similar solutions exist for other metal oxides used in pseudocapacitors, e.g., $\mathrm{RuO}_{2}$ or $\mathrm{Co}_{3} \mathrm{O}_{4}[221,253,254]$.

Currently, one of the new directions in supercapacitor development involves MOFs. These frameworks provide a template allowing better control and stabilizing the structure of the active material, leading to improved energy density and stability during the cycle life of the capacitor. MOF-based oxides can create a composite with carbon materials, such as graphene, graphene oxide, or nanotubes, to further improve their performance $[220,229,255]$.

Carbon materials can also be applied as current collectors. Typically, in supercapacitors, the current collectors have a form of a metallic foil or mesh, e.g. aluminum, nickel, or stainless steel $[236,245,256]$. A carbon material with an appropriate structure used in a collector can increase the contact area with the active material and improve corrosion resistance $[257,258]$. Porous carbon films or nanobrushes can be grown directly on various current collectors [236,255]. Alternatively, the whole collector can be replaced with nanotubes, graphene paper, or with porous carbon nanofoam [236,259].

Carbon can also be used as a binder in the construction of the supercapacitor, thereby increasing the available loading of the active material onto the current collectors. Typically, polymer-based binders are used (e.g. PTFE, PBI), but a bitumen-based paint can also be employed in this role [255].

Another interesting solution using carbon is represented by the electrode manufacture process. Electrodes can be printed using a carbon-based paint in the inkjet printing $[260,261]$. The carbon material can be utilized there to serve as both the active material and the current collector [262]. Supercapacitor electrodes can be printed using this technique with paint based on carbon material solution in a suitable solvent. A direct drawing using a graphite rod on cellulose paper can also be used to produce supercapacitor electrodes [263].

As shown above, carbon materials can be used in various elements of supercapacitors. This leads to a very broad range of materials used, from carbon-based paints to nanotubes. Regarding their use in the active material, composite materials and nanomaterials are especially promising candidates for future use. One of the important aspects when choosing the appropriate material is the balance between the capacity and cyclic stability, as an increase in the former parameter usually leads to a decrease in the latter.

Different avenues for obtaining carbon materials have also been studied. One of the more interesting sources of these materials is biological and organic waste. Using these sources of carbon can lead to the production of various materials used in more cost-effective and environmentally friendly energy storage [227]. In one study, Hoffman et al. prepared chars designed for use in supercapacitors from potato waste [264]. Rice husks can also be used as a substrate for the production of activated graphene-based supercapacitors $[265,266]$. Li et al. prepared flexible and self-healing supercapacitors using biochar based on soybean stover [267]. Supercapacitors were also prepared using porous carbon based on loofah sponge [268] or cicada sloughs [269]. 
In general, supercapacitors are characterized by a very high power and good cycle life at the cost of limited specific energy. Using carbon materials can help them achieve a better balance between capacity and power, broadening their application in areas such as electronics or electric vehicles, especially when applied in parallel with other power sources with a higher capacity but worse high-rate performance.

\section{Conclusions}

Carbon finds many uses in modern rechargeable batteries. Despite their very different characteristics, carbon can be applied in the construction of each of the presented types. Lead-acid battery properties can be greatly enhanced by using various forms of this element in their construction, allowing them to remain competitive with the more recent battery types. Carbon is one of the main reasons for the strong position of these batteries on the current market, while it also opens new avenues for future use and improvements. Currently, the focus of research on carbon modifications lies on the active mass, current collectors, and capacitor electrodes. The lithium-ion battery is another very popular battery type. In this case, the use of carbon was also one of the crucial elements that led to their dominant position. New types of carbon, including nanomaterials, are currently being used to further improve the properties of lithium batteries, with the bulk of this research focusing on novel anode materials. These materials are also a very important aspect for developing new types of rechargeable batteries. Both lithium-sulfur and sodium-ion batteries are very promising technologies that can replace currently used battery types. Carbon is used in Li-S batteries mostly in the cathodes, while it is used in sodium-ion batteries mainly in the anodes. Recent research on these batteries using carbon-based materials has shown great promise in overcoming their current drawbacks, which can lead to their mass usage in the future. Another electrochemical power source with good prospects for becoming widespread is represented by supercapacitors. Carbon can be used in them both as an active material in the carbon electrode (EDLCs) and as a part of the composite material in pseudocapacitors. Most studies on these materials have focused on improvements in specific energy.

Nanomaterials and composites often display superior properties compared to simpler materials, and they are a very important part of current developments in the reviewed power sources. At the same time, during the introduction of new materials, a balanced choice is often required. Improving one aspect of the battery performance can result in a decrease in other areas. These developments demand careful optimization, and the materials need to be chosen on the basis of the role of the power source. Aspects such as the working conditions, economical cost, or influence on other elements of the battery need to be considered in the selection of the best candidates for usage. Nevertheless, novel materials are being constantly developed, and reports of improvements in parameters of all power sources included in the review have been published.

Carbon is, therefore, a key element used in many materials in modern power sources, leading to more efficient energy storage. As such, it is an important part of the upcoming transformation of the global energy market into a more environmentally friendly structure, based on renewable sources. In this light, one of the important aspects is the source of the carbon materials, which can be derived from various biological sources, as shown in the current review. According to the information presented in this review, it can be concluded that carbon has allowed numerous improvements of battery properties in the past and will probably be crucial to many breakthroughs in the future of energy storage, leading to more efficient, cleaner, renewable energy.

Author Contributions: Conceptualization, J.L. and K.W.; investigation, J.L., K.W., J.W. and A.C.; writing—original draft preparation, J.L. and K.W.; writing—review and editing, J.L., K.W., J.W. and A.C.; visualization, J.L., K.W. and J.W.; supervision, A.C. All authors have read and agreed to the published version of the manuscript. 
Funding: This research was funded by the Łukasiewicz Research Network-Industrial Chemistry Institute and the Łukasiewicz Research Network-Institute for Engineering of Polymer Materials and Dyes. The APC was funded by the University of Warsaw. The research described in this paper was funded by the National Center for Research and Development LIDER Program under grant agreement No. LIDER/28/0148/L-10/18/NCBR/2019.

\section{Institutional Review Board Statement: Not applicable.}

Conflicts of Interest: The authors declare no conflict of interest.

\section{References}

1. United Nations Department of Economic and Social Affairs. Available online: https://population.un.org/wpp/Download/ Standard/Population/ (accessed on 11 March 2021).

2. An Official Website of the European Union. Available online: https:/ /ec.europa.eu/clima/policies/strategies/2050_en (accessed on 11 March 2021).

3. May, G.J.; Davidson, A.; Monahov, B. Lead Batteries for Utility Energy Storage: A review. J. Energy Storage 2018, 15, 145-157. [CrossRef]

4. Chen, S.; Qiu, L.; Cheng, H.M. Carbon-Based Fibers for Advanced Electrochemical Energy Storage Devices. Chem. Rev. 2020, 120, 2811-2878. [CrossRef] [PubMed]

5. Pethaiah, S.S.; Kumar, J.A.; Kalyani, P. Improvement in the Discharge Characteristics of Zinc-Carbon Primary Cells: A Comparative Study with Various Carbon Additives. Ionics 2011, 17, 339-342. [CrossRef]

6. Li, Y.; Wu, X.; Liu, C.; Wang, S.; Zhou, P.; Zhou, T.; Miao, Z.; Xing, W.; Zhuo, S.; Zhou, J. Fluorinated Multi-Walled Carbon Nanotubes as Cathode Materials of Lithium and Sodium Primary Batteries: Effect of Graphitization of Carbon Nanotubes. J. Mater. Chem. A 2019, 7, 7128-7137. [CrossRef]

7. Jayakumar, A. A Comprehensive Assessment on the Durability of Gas Diffusion Electrode Materials in PEM fuel cell stack. Front. Energy 2019, 13, 325-338. [CrossRef]

8. Banerjee, R.; Bevilacqua, N.; Mohseninia, A.; Wiedemann, B.; Wilhelm, F.; Scholta, J.; Zeis, R. Carbon Felt Electrodes for Redox Flow Battery: Impact of Compression on Transport Properties. J. Energy Storage 2019, 26, 100997. [CrossRef]

9. Mobasser, S.; Firoozi, A.A. Review of Nanotechnology Applications in Science and Engineering. J. Civ. Eng. Urban. 2016, 6, 84-93.

10. Punetha, V.D.; Rana, S.; Yoo, H.J.; Chaurasia, A.; McLeskey Jr., J.T.; Ramasamy, M.S.; Sahoo, N.G.; Cho, J.W. Functionalization of Carbon Nanomaterials for Advanced Polymernanocomposites: A Comparison Study Between CNT and Graphene. Prog. Polym. Sci. 2017, 67, 1-47. [CrossRef]

11. Rao, R.; Pint, C.L.; Islam, A.E.; Weatherup, R.S.; Hofmann, S.; Meshot, E.R.; Wu, F.; Zhou, C.; Dee, N.; Amama, P.B.; et al. Carbon Nanotubes and Related Nanomaterials: Critical Advances and Challenges for Synthesis toward Mainstream Commercial Applications. ACS Nano 2018, 12, 11756-11784. [CrossRef]

12. Pillot, C. Current Status and Future Trends of the Global Li-ion Battery Market; Avicenne Energy: London, UK, 2018.

13. Scopus Abstract \& Citation Database. Available online: https://www.scopus.com/ (accessed on 20 April 2021).

14. Pillot, C. The Rechargeable Battery Market and Main Trends 2016-2025; Avicenne Energy: Fort Lauderdale, FL, USA, 2017.

15. Linden, D.; Reddy, T.B. Handbook of Batteries, 3rd ed.; McGraw-Hill: New York, NY, USA, 2002; pp. 35.6-35.21.

16. Srinivasan, V. Batteries for Vehicular Applications. Am. Inst. Phys. 2008, 1044, 283-296.

17. Morris, M.; Tosunoglu, S. Comparison of Rechargeable Battery Technologies. Proceedings of ASME Early Career Technical Conference, Atlanta, GA, USA, 2-3 November 2012.

18. Winter, M.; Brood, R.J. What Are Batteries, Fuel Cells, and Supercapacitors? Chem. Rev. 2004, 104, 4245-4270.

19. Connolly, D. A Review of Energy Storage Technologies, version 3; University of Limerick: Limerick, Ireland, 2009.

20. Kurzweil, P.; Garche, J. Overview of Batteries for Future Automobiles. In Lead-Acid Batteries for Future Automobiles; Garche, J., Karden, E., Mosley, P.T., Rand, D.A.J., Eds.; Elsevier: Amsterdam, The Netherlands, 2017.

21. Abraham, K.M. How Comparable Are Sodium-Ion Batteries to Lithium-Ion Counterparts? ACS Energy Lett. 2020, 5, 3544-3547. [CrossRef]

22. Lopez, C.V.; Maladeniya, C.P.; Smith, R.C. Lithium-Sulfur Batteries: Advances and Trends. Electrochem 2020, 1, 226-259. [CrossRef]

23. Mandal, S.; Thangarasu, S.; Thong, P.T.; Kim, S.C.; Shim, J.Y.; Jung, H.Y. Positive Electrode Active Material Development Opportunities through Carbon Addition in the Lead-Acid Batteries: A Recent Progress. J. Power Sources 2021, 485, 229336. [CrossRef]

24. Xia, M.; Nie, J.; Zhang, Z.; Lu, X.; Wang, Z.L. Suppressing Self-Discharge of Supercapacitors via Electrorheological Effect of Liquid Crystals. Nano Energy 2018, 47, 43-50. [CrossRef]

25. Pavlov, D. Lead-Acid Batteries: Science and Technology; Elsevier B. V: Amsterdam, The Netherlands, 2011; pp. $22-23$.

26. Lach, J.; Wróbel, K.; Wróbel, J.; Podsadni, P.; Czerwiński, A. Applications of Carbon in Lead-Acid Batteries: A Review. J. Solid State Electrochem. 2019, 23, 693-705. [CrossRef]

27. Hao, Z.; Xu, X.; Wang, H.; Liu, J.; Yan, H. Review on the Roles of Carbon Materials in Lead-Carbon Batteries. Ionics 2018, 24, 951-965. [CrossRef]

28. Moseley, P.T.; Rand, D.A.J.; Peters, K. Enhancing the Performance of Lead-Acid Batteries with Carbon-In Pursuit of an Understanding. J. Power Sources 2015, 295, 268-274. [CrossRef] 
29. Moseley, P.T.; Rand, D.A.J.; Davidson, A.; Monahov, B. Understanding the Functions of Carbon in the Negative Active-Mass of the Lead-Acid Battery: A Review of Progress. J. Energy Storage 2018, 19, 272-290. [CrossRef]

30. Ebner, E.; Burow, D.; Panke, J.; Börger, A.; Feldhoff, A.; Atanassova, P.; Valenciano, J.; Wark, M.; Rühl, E. Carbon Blacks for Lead-Acid Batteries in Micro-Hybrid Applications-Studied by Transmission Electron Microscopy and Raman Spectroscopy. J. Power Sources 2013, 222, 554-560. [CrossRef]

31. Wang, L.; Zhang, H.; Zhang, W.; Cao, G.; Zhao, H.; Yang, Y. Enhancing Cycle Performance of Lead-Carbon Battery Anodes by Lead-Doped Porous Carbon Composite and Graphite Additives. Mater. Lett. 2017, 206, 113-116. [CrossRef]

32. Blecua, M.; Fatas, E.; Ocon, P.; Gonzalo, B.; Merino, C.; de la Fuente, F.; Valenciano, J.; Trinidad, F. Graphitized Carbon Nanofibers: New Additive for the Negative Active Material of Lead Acid Batteries. Electrochim. Acta 2017, 257, 109-117. [CrossRef]

33. Mahajan, V.; Bharj, R.S.; Bharj, J. Role of Nano-Carbon Additives in Lead-Acid Batteries: A Review. Bull. Mater. Sci. 2019, 42, 21. [CrossRef]

34. Marom, R.; Ziv, B.; Banerjee, A.; Cahana, B.; Luski, S.; Aurbach, D. Enhanced Performance of Starter Lighting Ignition Type Lead-Acid Batteries with Carbon Nanotubes as an Additive to the Active Mass. J. Power Sources 2015, 296, 78-85. [CrossRef]

35. Hu, H.Y.; Xie, N.; Wang, C.; Wu, F.; Pan, M.; Li, H.F.; Wu, P.; Wang, X.D.; Zeng, Z.; Deng, S.; et al. Enhancing the Performance of Motive Power Lead-Acid Batteries by High Surface Area Carbon Black Additives. Appl. Sci. 2019, 9, 186. [CrossRef]

36. Logeshkumar, S.; Manoharan, R. Influence of Some Nanostructured Materials Additives on the Performance of Lead Acid Battery Negative Electrodes. Electrochim. Acta 2014, 144, 147-153. [CrossRef]

37. Jiang, Y.; Zhu, H.; Yu, C.; Cao, X.; Cheng, L.; Li, R.; Yang, S.; Dai, C. Effects of Carbon Additives on the HRPSoC Performance of Lead Carbon Batteries and Their Low Temperature Performance. Int. J. Electrochem. Sci. 2017, 12, 10882-10893. [CrossRef]

38. Wang, L.; Zhang, H.; Zhang, W.; Guod, H.; Cao, G.; Zhao, H.; Yang, Y. A New Nano Lead-Doped Mesoporous Carbon Composite as Negative Electrode Additives for Ultralong-Cyclability Lead-Carbon Batteries. Chem. Eng. J. 2018, 337, 201-209. [CrossRef]

39. Hong, B.; Jiang, L.; Xue, H.; Liu, F.; Jia, M.; Li, J.; Liu, Y. Characterization of Nano-Lead-Doped Active Carbon and its Application in Lead-Acid Battery. J Power Sources 2014, 270, 332-341. [CrossRef]

40. Wang, F.; Hu, C.; Lian, J.; Zhou, M.; Wang, K.; Yan, J.; Jiang, K. Phosphorus-Doped Activated Carbon as a Promising Additive for High Performance Lead Carbon Batteries. RSC Adv. 2017, 7, 4174-4178. [CrossRef]

41. Hong, B.; Yu, X.; Jiang, L.; Xue, H.; Liu, F.; Li, Y.; Liu, Y. Hydrogen Evolution Inhibition with Diethylenetriamine Modification of Activated Carbon for a Lead-Acid Battery. RSC Adv. 2014, 4, 33574-33577. [CrossRef]

42. Ball, R.J.; Evans, R.; Thacker, E.L.; Stevens, R. Effect of Valve Regulated Lead/Acid Battery Positive Paste Carbon Fibre Additive. J. Mater. Sci. 2003, 38, 3013-3017. [CrossRef]

43. Hao, H.; Chen, K.; Liu, H.; Wang, H.; Liu, J.; Yang, K.; Yan, H. A Review of the Positive Electrode Additives in Lead-Acid Batteries. Int. J. Electrochem. Sci. 2018, 13, 2329-2340. [CrossRef]

44. Banerjee, A.; Ziv, B.; Shilina, Y.; Levi, E.; Luski, S.; Aurbach, D. Single-Wall Carbon Nanotube Doping in Lead-Acid Batteries: A New Horizon. ACS Appl. Mater. Interfaces 2017, 9, 3634-3643. [CrossRef]

45. Shen, H.; Jin, Y.; Zhao, Z.; Sun, Y.; Huang, B.; Wang, J. Preparation of Graphite-Based Lead Carbon Cathode and its Performance of Batteries. Micro Nano Lett. 2019, 14, 915-918. [CrossRef]

46. Shi, J.; Lin, N.; Wang, Y.; Liu, D.; Lin, H. The Application of Rice Husk-Based Porous Carbon in Positive Electrodes of Lead Acid Batteries. J. Energy Storage 2020, 30, 101392. [CrossRef]

47. Yin, J.; Lin, N.; Lin, Z.; Wang, Y.; Chen, C.; Shi, J.; Bao, J.; Lin, H.; Feng, S.; Zhang, W. Hierarchical Porous Carbon@PbO1-x Composite for High-Performance Lead-Carbon Battery Towards Renewable Energy Storage. Energy 2020, 193, 116675. [CrossRef]

48. Czerwiński, A. Sposób Galwanicznego Nanoszenia Ołowiu lub Tlenku Ołowiowego na Przewodzące Materiały Węglowe. RP Patent 167796, 12 May 1995.

49. Czerwiński, A.; Żelazowska, M. Electrochemical Behavior of Lead Deposited on Reticulated Vitreous Carbon. J. Electroanal. Chem. 1996, 410, 55-60. [CrossRef]

50. Czerwiński, A.; Żelazowska, M. Electrochemical Behavior of Lead Dioxide Deposited on Reticulated Vitreous carbon (RVC). J. Power Sources 1997, 64, 29-34. [CrossRef]

51. Czerwiński, A.; Obrębowski, S.; Kotowski, J.; Rogulski, Z.; Skowroński, J.; Bajsert, M.; Przystałowski, M.; Buczkowska-Biniecka, M.; Jankowska, E.; Baraniak, M.; et al. Hybrid Lead-Acid Battery with Reticulated Vitreous Carbon as a Carrier- and CurrentCollector of Negative Plate. J. Power Sources 2010, 195, 7530-7534. [CrossRef]

52. Gyenge, E.; Jung, J.; Mahato, B. Electroplated Reticulated Vitreous Carbon Current Collectors for Lead-Acid Batteries: Opportunities and Challenges. J. Power Sources 2003, 113, 388-395. [CrossRef]

53. Czerwiński, A.; Rogulski, Z.; Obrębowski, S.; Lach, J.; Wróbel, K.; Wróbel, J. Positive Plate for Carbon Lead-Acid Battery. Int. J. Electrochem. Sci. 2014, 9, 4826-4839.

54. Czerwiński, A.; Wróbel, J.; Lach, J.; Wróbel, K.; Podsadni, P. The Charging-Discharging Behavior of the Lead-Acid Cell with Electrodes Based on Carbon Matrix. J. Solid State Electrochem. 2018, 22, 2703-2714. [CrossRef]

55. Kirchev, A.; Serra, L.; Dumenil, S.; Brichard, G.; Alias, M.; Jammet, B.; Vinit, L. Carbon Honeycomb Grids for Advanced Lead-Acid Batteries. Part III: Technology Scale-Up. J. Power Sources 2015, 299, 324-333. [CrossRef]

56. Jang, Y.I.; Dudney, N.J.; Tiegs, T.N.; Klett, J.W. Evaluation of the Electrochemical Stability of Graphite Foams as Current Collectors for Lead Acid Batteries. J. Power Sources 2006, 161, 1392-1399. [CrossRef] 
57. Ma, L.W.; Chen, B.Z.; Chen, Y.; Yuan, Y. Pitch-Based Carbon Foam Electrodeposited with Lead as Positive Current Collectors for Lead Acid Batteries. J. Appl. Electrochem. 2009, 39, 1609-1615. [CrossRef]

58. Chen, Y.; Chen, B.Z.; Shi, X.C.; Xu, H.; Shang, W.; Yuan, Y.; Xiao, L.P. Preparation and Electrochemical Properties of Pitch-Based Carbon Foam as Current Collectors for Lead Acid Batteries. Electrochim. Acta 2008, 53, 2245-2249. [CrossRef]

59. Lannelongue, J.; Cugnet, M.; Guillet, N.; Kirchev, A. Electrochemistry of Thin-Plate Lead-Carbon Batteries Employing Alternative Current Collectors. J. Power Sources 2017, 352, 194-207. [CrossRef]

60. Hariprakash, B.; Gaffoor, S.A. Lead-Acid Cells with Lightweight, Corrosion-Protected, Flexible-Graphite Grids. J. Power Sources 2007, 173, 565-569. [CrossRef]

61. Zhang, S.; Zhang, H.; Cheng, J.; Zhang, W.; Cao, G.; Zhao, H.; Yang, Y. Novel Polymer-Graphite Composite Grid as a Negative Current Collector for Lead-Acid Batteries. J. Power Sources 2016, 334, 31-38. [CrossRef]

62. Kirchev, A.; Kircheva, N.; Perrin, M. Carbon Honeycomb Grids for Advanced Lead-Acid Batteries. Part I: Proof of Concept. J. Power Sources 2011, 196, 8773-8788. [CrossRef]

63. Kirchev, A.; Dumenil, S.; Alias, M.; Christin, R.; de Mascarel, A.; Perrin, M. Carbon Honeycomb Grids for Advanced Lead-Acid Batteries. Part II: Operation of the Negative Plates. J. Power Sources 2015, 279, 809-824. [CrossRef]

64. Christie, S.; Wong, Y.S.; Titelman, G.; Abrahamson, J. Lead-Acid Battery Construction. US Patent 9543589, 10 January 2017.

65. Lam, L.T.; Louey, R. Development of Ultra-Battery for Hybrid-Electric Vehicle Applications. J. Power Sources 2006, 158, 1140-1148. [CrossRef]

66. Cooper, A.; Furakawa, J.; Lam, L.; Kellaway, M. The UltraBattery-A New Battery Design for a New Beginning in Hybrid Electric Vehicle Energy Storage. J. Power Sources 2009, 188, 642-649. [CrossRef]

67. Monahov, B. The beneficial Role of Carbon in the Negative Plate of Advanced Lead-Carbon Batteries. Ecs Trans. 2012, 41, 45-69. [CrossRef]

68. Broussely, M.; Pistoia, G. Industrial Applications of Batteries, 1st ed.; Elsevier: London, UK, 2007; pp. 2-28.

69. Tarascon, J.M.; Armand, M. Issues and Challenges Facing Rechargeable Lithium Batteries. Nature 2001, 414, 359-367. [CrossRef] [PubMed]

70. Goriparti, S.; Miele, E.; De Angelis, F.; Di Fabrizio, E.; Zaccaria, R.P.; Capigila, C. Review on Recent Progress of Nanostructured Anode Materials for Li-ion Batteries. J. Power Sources 2014, 257, 421-443. [CrossRef]

71. Ratynski, M.; Hamankiewicz, B.; Krajewski, M.; Boczar, M.; Ziolkowska, D.; Czerwinski, A. Impact of Natural and Synthetic Graphite Milling Energy on Lithium-Ion Electrode Capacity and Cycle Life. Carbon 2019, 145, 82-89. [CrossRef]

72. Park, C.M.; Choi, W.; Hwa, Y.; Kim, J.H.; Jeong, G.; Sohn, H.J. Characterizations and Electrochemical Behaviors of Disproportionated $\mathrm{SiO}$ and its Composite for Rechargeable Li-ion Batteries. J. Mater. Chem. 2010, 20, 4854-4860. [CrossRef]

73. Pistoia, G. Lithium Batteries-New Materials, Developments and Perspectives; Elsevier: New York, NY, USA, $1994 ;$ pp. 1-97.

74. Chen, Z.; Wang, Q.; Amine, K. Improving the Performance of Soft Carbon for Lithium-Ion Batteries. Electrochim. Acta 2006, 51, 3890-3894. [CrossRef]

75. Sato, K.; Noguchi, M.; Demachi, A.; Oki, N.; Endo, M. A Mechanism of Lithium Storage in Disordered Carbons. Science 1994, 264, 556-558. [CrossRef] [PubMed]

76. Dahn, J.R.; Zheng, T.; Liu, Y.; Xue, J.S. Mechanisms for Lithium Insertion in Carbonaceous Materials. Science 1995, 270, 590-593. [CrossRef]

77. Papanek, P.; Radosavljevic, M.; Fischer, J.E. Lithium Insertion in Disordered Carbon-Hydrogen Alloys: Intercalation vs Covalent Binding. Chem. Mater. 1996, 8, 1519-1526. [CrossRef]

78. Fujimoto, H.; Tokumitsu, K.; Mubuchi, A.; Chinnasamy, N.; Kasuh, T. The Anode Performance of the Hard Carbon for the Lithium Ion Battery Derived from the Oxygen-Containing Aromatic Precursors. J. Power Sources 2010, 195, 7452-7456. [CrossRef]

79. Wang, J.; Liu, J.L.; Wang, Y.G.; Wang, C.X.; Xia, Y.Y. Pitch Modified Hard Carbons as Negative Materials for Lithium-Ion Batteries. Electrochim. Acta 2012, 74, 1-7. [CrossRef]

80. Hu, J.; Li, H.; Huang, X. Influence of Micropore Structure on Li-Storage Capacity in Hard Carbon Spherules. Solid State Ion. 2005, 176, 1151-1159. [CrossRef]

81. Rao, X.; Lou, Y.; Chen, J.; Lu, H.; Cheng, B.; Wang, W.; Fang, H.; Li, H.; Zhong, S. Polyacrylonitrile Hard Carbon as Anode of High Rate Capability for Lithium Ion Batteries. Front. Energy Res. 2020, 8, 3. [CrossRef]

82. Li, W.; Chen, M.; Wang, C. Spherical Hard Carbon Prepared from Potato Starch Using as Anode Material for Li-ion Batteries. Mater. Lett. 2011, 65, 3368-3370. [CrossRef]

83. Yang, J.; Zhou, X.Y.; Li, J.; Zou, Y.L.; Tang, J.J. Study of Nano-Porous Hard Carbons as Anode Materials for Lithium Ion Batteries. Mater. Chem. Phys. 2012, 135, 445-450. [CrossRef]

84. Zhao, J.; Buldum, A.; Han, J.; Ping, J. First-Principles Study of Li-Intercalated Carbon Nanotube Ropes. Phys. Rev. Lett. 2000, 85, 1706-1709. [CrossRef]

85. Meunier, V.; Kephart, J.; Roland, C.; Bernholc, J. Ab Initio Investigations of Lithium Diffusion in Carbon Nanotube Systems. Phys. Rev. Lett. 2002, 88, 075506-01. [CrossRef] [PubMed]

86. Schauermann, C.M.; Ganter, M.J.; Gaustad, G.; Babbitt, C.W.; Raffaelle, R.P.; Landi, B.J. Recycling Single-Wall Carbon Nanotube Anodes from Lithium Ion Batteries. J. Mater. Chem. 2012, 22, 12008-12015. [CrossRef]

87. Yu, Y.; Cui, C.; Qian, W.; Xie, Q.; Zheng, C.; Kong, C.; Wei, F. Carbon Nanotube Production and Application in Energy Storage. Asia-Pac. J. Chem. Eng. 2013, 8, 234-245. [CrossRef] 
88. Lv, R.; Zou, L.; Gui, X.; Kang, F.; Zhu, Y.; Zhu, H.; Wei, J.; Gu, J.; Wang, K.; Wu, D. High-Yield Bamboo-Shaped Carbon Nanotubes from Cresol for Electrochemical Application. Chem. Commun. 2008, 2046-2048. [CrossRef]

89. Zhou, J.; Song, H.; Fu, B.; Wu, B.; Chen, X. Synthesis and High-Rate Capability of Quadrangular Carbon Nanotubes with One Open end as Anode Materials for Lithium-Ion Batteries. J. Mater. Chem. 2010, 20, 2794-2800. [CrossRef]

90. Oktaviano, H.S.; Yamada, K.; Waki, K. Nano-Drilled Multiwalled Carbon Nanotubes: Characterizations and Application for LIB Anode Materials. J. Mater. Chem. 2012, 22, 25167. [CrossRef]

91. Landi, B.J.; Ganter, M.J.; Cress, C.D.; DiLeo, R.A.; Raffaelle, R.P. Carbon Nanotubes for Lithium Ion Batteries. Energy Environ. Sci. 2009, 2, 638-654. [CrossRef]

92. DiLeo, R.A.; Castiglia, A.; Ganter, M.J.; Rogers, R.E.; Cress, C.D.; Raffaelle, R.P.; Landi, B.J. Enhanced Capacity and Rate Capability of Carbon Nanotube Based Anodes with Titanium Contacts for Lithium Ion Batteries. ACS Nano 2010, 4, 6121-6131. [CrossRef]

93. Wang, B.; Li, X.; Zhang, X.; Luo, B.; Jin, M.; Liang, M.; Dayeh, S.A.; Picraux, S.T.; Zhi, L. Adaptable Silicon-Carbon Nanocables Sandwiched between Reduced Graphene Oxide Sheets as Lithium Ion Battery Anodes. ACS Nano 2013, 7, 1437-1445. [CrossRef]

94. Zhang, X.; Ji, L.; Toprakci, O.; Liang, Y.; Alcoutlabi, M. Electrospun Nanofiber-Based Anodes, Cathodes, and Separators for Advanced Lithium-Ion Batteries. Polym. Rev. 2011, 51, 239-264. [CrossRef]

95. Wu, Y.; Wei, Y.; Wang, J.; Jiang, K.; Fan, S. Conformal $\mathrm{Fe}_{3} \mathrm{O}_{4}$ Sheath on Aligned Carbon Nanotube Scaffolds as High-Performance Anodes for Lithium Ion Batteries. Nano Lett. 2013, 13, 818-823. [CrossRef] [PubMed]

96. Sehrawat, P.; Julien, C.; Islam, S.S. Carbon Nanotubes in Li-ion Batteries: A Review. Mater. Sci. Eng. B 2016, 213, 12-40. [CrossRef]

97. Chen, S.; Shen, L.; van Aken, P.A.; Maier, J.; Yu, Y. Dual-Functionalized Double Carbon Shells Coated Silicon Nanoparticles for High Performance Lithium-Ion Batteries. Adv. Mater. 2017, 1605650. [CrossRef] [PubMed]

98. Wang, X.; Chen, K.; Wang, G.; Liu, X.; Wang, H. Rational Design of Three-Dimensional Graphene Encapsulated with Hollow FeP@Carbon Nanocomposite as Outstanding Anode Material for Lithium Ion and Sodium Ion Batteries. ACS Nano 2017, 11, 11602-11616. [CrossRef] [PubMed]

99. Lin, C.; Hu, L.; Cheng, C.; Sun, K.; Guo, X.; Shao, Q.; Li, J.; Wang, N.; Guo, Z. Nano-TiNb ${ }_{2} \mathrm{O}_{7} /$ Carbon Nanotubes Composite Anode for Enhanced Lithium-Ion Storage. Electrochim. Acta 2018, 260, 65-72. [CrossRef]

100. Pan, D.; Wang, S.; Zhao, B.; Wu, M.; Zhang, H.; Wang, Y.; Jiao, Z. Li Storage Properties of Disordered Graphene Nanosheets. Chem. Mater. 2009, 21, 3136-3142. [CrossRef]

101. Hou, J.; Shao, Y.; Ellis, M.W.; Moore, R.B.; Yi, B. Graphene-Based Electrochemical Energy Conversion and Storage: Fuel Cells, Supercapacitors and Lithium Ion Batteries. Phys. Chem. Chem. Phys. 2011, 13, 15384-15402. [CrossRef]

102. Hwang, H.J.; Koo, J.; Park, M.; Park, N.; Kwon, Y.; Lee, H. Multilayer Graphynes for Lithium Ion Battery Anode. J. Phys. Chem. C 2013, 117, 6919-6923. [CrossRef]

103. Lian, P.; Zhu, X.; Liang, S.; Li, Z.; Yang, W.; Wang, H. Large Reversible Capacity of High Quality Graphene Sheets as an Anode Material for Lithium-Ion Batteries. Electrochim. Acta 2010, 55, 3909-3914. [CrossRef]

104. Wang, Z.L.; Xu, D.; Wang, H.G.; Wu, Z.; Zhang, X.B. In Situ Fabrication of Porous Graphene Electrodes for High-Performance Energy Storage. ACS Nano 2013, 7, 2422-2430. [CrossRef] [PubMed]

105. Vinayan, B.P.; Ramaprabhu, S. Facile Synthesis of $\mathrm{SnO}_{2}$ Nanoparticles Dispersed Nitrogen Doped Graphene Anode Material for Ultrahigh Capacity Lithium Ion Battery Applications. J. Mater. Chem. A 2013, 1, 3865-3871. [CrossRef]

106. Hu, A.; Chen, X.; Tang, Y.; Tang, Q.; Yang, L.; Zhang, S. Self-assembly of $\mathrm{Fe}_{3} \mathrm{O}_{4}$ Nanorods on Graphene for Lithium Ion Batteries with High Rate Capacity and Cycle Stability. Electrochem. Commun. 2013, 28, 139-142. [CrossRef]

107. Zhao, B.; Ran, R.; Liu, M.; Shao, Z. A Comprehensive Review of $\mathrm{Li}_{4} \mathrm{Ti}_{5} \mathrm{O}_{12}$-based Electrodes for Lithium-Ion Batteries: The latest Advancements and Future Perspectives. Mater. Sci. Eng. R 2015, 98, 1-71. [CrossRef]

108. Fu, R.; Zhou, X.; Fan, H.; Blaisdell, D.; Jagadale, A.; Zhang, X.; Xiong, R. Comparison of Lithium-Ion Anode Materials Using an Experimentally Verified Physics-Based Electrochemical Model. Energies 2017, 10, 2174. [CrossRef]

109. Liu, J.; Wei, A.X.; Chen, M.; Xia, X. Rational synthesis of $\mathrm{Li}_{4} \mathrm{Ti}_{5} \mathrm{O}_{12} / \mathrm{N}-\mathrm{C}$ Nanotube Arrays as Advanced High-Rate Electrodes for Lithium-Ion Batteries. J. Mater. Chem. A 2018, 6, 3857-3863. [CrossRef]

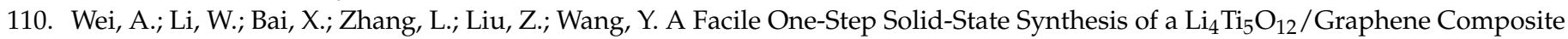
as an Anode Material for High-Power Lithium-Ion Batteries. Solid State Ion. 2019, 329, 110-118. [CrossRef]

111. Wei, A.; Mu, J.; He, R.; Bai, X.; Liu, Z.; Zhang, L.; Liu, Z.; Wang, Y. Preparation of $\mathrm{Li}_{4} \mathrm{Ti}_{5} \mathrm{O}_{12} /$ Carbon Nanotubes Composites and $\mathrm{LiCoO}_{2} / \mathrm{Li}_{4} \mathrm{Ti}_{5} \mathrm{O}_{12}$ Full-Cell with Enhanced Electrochemical Performance for High-Power Lithium-Ion Batteries. J. Phys. Chem. Solids 2020, 138, 109303. [CrossRef]

112. Lan, C.K.; Bao, Q.; Huang, Y.H.; Duh, J.G. Embedding nano- $\mathrm{Li}_{4} \mathrm{Ti}_{5} \mathrm{O}_{12}$ in Hierarchical Porous Carbon Matrixes Derived from Water Soluble Polymers for Ultra-Fast Lithium Ion Batteries Anodic Materials. J. Alloys Compd. 2016, 673, 336-348. [CrossRef]

113. Yao, N.Y.; Liu, H.K.; Liang, X.; Sun, Y.; Feng, X.Y.; Chen, C.H.; Xinag, H.F. Li ${ }_{4} \mathrm{Ti}_{5} \mathrm{O}_{12}$ Nanosheets Embedded in Three-Dimensional Amorphous Carbon for Superior-Rate Battery Applications. J. Alloys Compd. 2019, 771, 755-761. [CrossRef]

114. Stenina, I.; Shaydullin, R.; Kulova, T.; Kuzmina, A.; Tabachkova, N.; Yoroslavtsev, A. Effect of Carbon Additives on the Electrochemical Performance of $\mathrm{Li}_{4} \mathrm{Ti}_{5} \mathrm{O}_{12} / \mathrm{C}$ Anodes. Energies 2020, 13, 3941. [CrossRef]

115. Shen, L.; Lv, H.; Chen, S.; Kopold, P.; van Aken, P.A.; Wu, X.; Maier, J.; Yu, Y. Peapod-like $\mathrm{Li}_{3} \mathrm{VO}_{4} / \mathrm{N}^{-D o p e d}$ Carbon Nanowires with Pseudocapacitive Properties as Advanced Materials for High-Energy Lithium-Ion Capacitors. Adv. Mater. 2017, 29, 1700142. [CrossRef] 
116. Sun, X.; Zhang, X.; Liu, W.; Wang, K.; Li, C.; Li, Z.; Ma, Y. Electrochemical Performances and Capacity Fading Behaviors of Activated Carbon/Hard Carbon Lithium Ion Capacitor. Electrochim. Acta 2017, 235, 158-166. [CrossRef]

117. Decaux, C.; Lota, G.; Raymoundo-Piñero, E.; Frąckowiak, E.; Béguin, F. Electrochemical Performance of a Hybrid Lithium-Ion Capacitor with a Graphite Anode Preloaded from Lithium Bis(Trifluoromethane)Sulfonimide-Based Electrolyte. Electrochim. Acta 2012, 86, 282-286. [CrossRef]

118. Brückner, J.; Thieme, S.; Böttger-Hiller, F.; Bauer, I.; Grossmann, H.T.; Strubel, P.; Althues, H.; Spange, S.; Kaskel, S. Carbon-Based Anodes for Lithium Sulfur Full Cells with High Cycle Stability. Adv. Funct. Mater. 2014, 24, 1284-1289. [CrossRef]

119. Zhu, S.; Li, Y. Carbon-Metal Oxide Nanocomposites as Lithium-Sulfur Battery Cathodes. Funct. Mater. Lett. 2018, 11, 1830007. [CrossRef]

120. Donoro, A.; Cintora-Juarez, D.; Etacheri, V. Carbon Nanomaterials for Rechargeable Lithium-Sulfur Batteries. In Carbon Based Nanomaterials for Advanced Thermal and Electrochemical Energy Storage and Conversion; Paul, R., Etacheri, V., Wang, Y., Lin, C.T., Eds.; Elsevier: Amsterdam, The Netherlands, 2019; pp. 279-309.

121. Zhang, X.Q.; Liu, C.; Gao, Y.; Zhang, J.M.; Wang, Y.Q. Research Progress of Sulfur/Carbon Composite Cathode Materials and the Corresponding Safe Electrolytes for Advanced Li-S Batteries. Nano 2020, 15, 2030002. [CrossRef]

122. Kang, H.; Kim, H.; Park, M.J. Sulfur-Rich Polymers with Functional Linkers for High-Capacity and Fast-Charging Lithium-Sulfur Batteries. Adv. Energy Mater. 2018, 8, 1802423. [CrossRef]

123. Fang, R.; Chen, K.; Yin, L.; Sun, Z.; Li, F.; Cheng, H.M. The Regulating Role of Carbon Nanotubes and Graphene in Lithium-Ion and Lithium-Sulfur Batteries. Adv. Mater. 2019, 31, 1800863. [CrossRef]

124. Sun, J.; Ma, J.; Fan, J.; Pyun, J.; Geng, J. Rational Design of Sulfur-Containing Composites for High-Performance Lithium-Sulfur Batteries. Apl Mater. 2019, 7, 020904. [CrossRef]

125. Thangavel, R.; Kannan, A.G.; Ponraj, R.; Kaliyappan, K.; Yoon, W.S.; Kim, D.W.; Lee, Y.S. Cinnamon-Derived Hierarchically Porous Carbon as an Effective Lithium Polysulfide Reservoir in Lithium-Sulfur Batteries. Nanomaterials 2020, 10, 1220. [CrossRef]

126. Cai, Y.; Guo, Y.; Jiang, B.; Lv, Y. Encapsulation of Cathode in Lithium-Sulfur Batteries with a Novel Two-Dimensional Carbon Allotrope: DHP-Graphene. Sci. Rep. 2017, 7, 14948. [CrossRef]

127. Zhang, B.; Xiao, M.; Wang, S.; Han, D.; Song, S.; Chen, G.; Meng, Y. Novel Hierarchically Porous Carbon Materials Obtained from Natural Biopolymer as Host Matrixes for Lithium-Sulfur Battery Applications. ACS Appl. Mater. Interfaces 2014, 6, 13174-13182. [CrossRef]

128. Fang, X.; Peng, H. A Revolution in Electrodes: Recent Progress in Rechargeable Lithium-Sulfur Batteries. Small 2015, 11, 1488-1511. [CrossRef]

129. Li, S.; Jin, B.; Zhai, X.; Li, H.; Jiang, Q. Review of Carbon Materials for Lithium-Sulfur Batteries. ChemistrySelect 2018, 3, 2245-2260. [CrossRef]

130. Zhang, Y.; Peng, Y.; Wang, Y.; Li, J.; Li, H.; Zeng, J.; Wang, J.; Hwang, B.J.; Zhao, J. High Sulfur-Containing Carbon Polysulfide Polymer as a Novel Cathode Material for Lithium-Sulfur Battery. Sci. Rep. 2017, 7, 11386. [CrossRef] [PubMed]

131. Rosenman, A.; Markevich, E.; Salitra, G.; Aurbach, D.; Garsuch, A.; Chesneau, F.F. Review on Li-Sulfur Battery Systems: An Integral Perspective. Adv. Energy Mater. 2015, 5, 1500212. [CrossRef]

132. Mao, Y.; Li, G.; Guo, Y.; Li, Z.; Liang, C.; Peng, X.; Lin, Z. Foldable Interpenetrated Metal-Organic Frameworks/Carbon Nanotubes Thin Film for Lithium-Sulfur Batteries. Nat. Commun. 2017, 8, 14628. [CrossRef] [PubMed]

133. Tan, H.; Wang, S.; Tao, D.; Yang, Z. Acetylene Black/Sulfur Composites Synthesized by a Solution Evaporation Concentration Crystallization Method and Their Electrochemical Properties for Li/S Batteries. Energies 2013, 6, 3466-3480. [CrossRef]

134. Fu, A.; Wang, C.; Pei, F.; Cui, J.; Fang, X.; Zhen, N. Recent Advances in Hollow Porous Carbon Materials for Lithium-Sulfur Batteries. Small 2019, 15, 1804786. [CrossRef]

135. Li, Z.; Yuan, L.; Yi, Z.; Sun, Y.; Liu, Y.; Jiang, Y.; Shen, Y.; Xin, Y.; Zhang, Z.; Huang, Y. Insight into the Electrode Mechanism in Lithium-Sulfur Batteries with Ordered Microporous Carbon Confined Sulfur as the Cathode. Adv. Energy Mater. 2014, 4, 1301473. [CrossRef]

136. Zhang, L.; Huang, H.; Xia, Y.; Liang, C.; Zhang, W.; Luo, J.; Gan, Y.; Zhang, J.; Tao, X.; Fan, H.J. High-Content of Sulfur Uniformly Embedded in Mesoporous Carbon: A New Electrodeposition Synthesis and an Outstanding Lithium-Sulfur Battery Cathode. J. Mater. Chem. A 2017, 5, 5905-5911. [CrossRef]

137. Yang, X.; Zhang, L.; Zhang, F.; Huang, Y.; Chen, Y. Sulfur-Infiltrated Graphene-Based Layered Porous Carbon Cathodes for High-Performance Lithium Sulfur Batteries. ACS Nano 2014, 8, 5208-5215. [CrossRef]

138. Fang, R.; Zhao, S.; Pei, S.; Qian, X.; Hou, P.X.; Cheng, H.M.; Liu, C.; Li, F. Toward More Reliable Lithium-Sulfur Batteries: An All-Graphene Cathode Structure. ACS Nano 2016, 10, 8676-8682. [CrossRef] [PubMed]

139. Kim, S.; Song, H.; Jeong, Y. Flexible catholyte@carbon Nanotube Film Electrode for High-Performance Lithium Sulfur Battery. Carbon 2017, 113, 371-378. [CrossRef]

140. Chen, L.; Zhou, H.; Fu, C.; Chen, Z.; Xu, C.; Kuang, Y. Chemical Modification of Pristine Carbon Nanotubes and their Exploitation as the Carbon Hosts for Lithium-Sulfur Batteries. Int. J. Hydrog. Energy 2016, 41, 21850-21860. [CrossRef]

141. Razzaq, A.A.; Yao, Y.; Shah, R.; Qi, P.; Miao, L.; Chen, M.; Zhao, X.; Peng, Y.; Deng, Z. High-Performance Lithium Sulfur Batteries Enabled by a Synergy Between Sulfur and Carbon Nanotubes. Energy Storage Mater. 2019, 16, 194-202. [CrossRef]

142. Gueon, D.; Hwang, J.T.; Yang, S.B.; Cho, E.; Sohn, K.; Yang, D.K.; Moon, J.H. Spherical Macroporous Carbon Nanotube Particles with Ultrahigh Sulfur Loading for Lithium-Sulfur Battery Cathodes. ACS Nano 2018, 12, 226-233. [CrossRef] 
143. Zhang, L.; Wang, Y.; Niu, Z.; Chen, J. Advanced Nanostructured Carbon-Based Materials for Rechargeable Lithium-Sulfur Batteries. Carbon 2019, 141, 400-416. [CrossRef]

144. Deng, W.; Hu, A.; Chen, X.; Zhang, S.; Tang, Q.; Liu, Z.; Fan, B.; Xiao, K. Sulfur-Impregnated 3D Hierarchical Porous Nitrogen-Doped Aligned Carbon Nanotubes as High-Performance Cathode for Lithium-Sulfur Batteries. J. Power Sources 2016, 322, 138-146. [CrossRef]

145. Ponraj, R.; Kannan, A.G.; Ahn, J.H.; Lee, J.H.; Kang, J.; Han, B.; Kim, D.W. Effective Trapping of Lithium Polysulfides Using a Functionalized Carbon Nanotube-Coated Separator for Lithium-Sulfur Cells with Enhanced Cycling Stability. ACS Appl. Mater. Interfaces 2017, 9, 38445-38454. [CrossRef]

146. Yang, X.; Yu, Y.; Yan, N.; Zhang, H.; Li, X.; Zhang, H. 1-D Oriented Cross-Linking Hierarchical Porous Carbon Fibers as a Sulfur Immobilizer for High Performance Lithium-Sulfur Batteries. J. Mater. Chem. A 2016, 4, 5965-5972. [CrossRef]

147. Yun, J.H.; Kim, J.H.; Kim, D.K.; Lee, H.W. Suppressing Polysulfide Dissolution via Cohesive Forces by Interwoven Carbon Nanofibers for High-Areal-Capacity Lithium-Sulfur Batteries. Nano Lett. 2018, 18, 475-481. [CrossRef]

148. Lee, J.S.; Kim, W.; Jang, J.; Manthiram, A. Sulfur-Embedded Activated Multichannel Carbon Nanofiber Composites for Long-Life, High-Rate Lithium-Sulfur Batteries. Adv. Energy Mater. 2017, 7, 1601943. [CrossRef]

149. Zheng, G.; Zhang, Q.; Cha, J.J.; Yang, Y.; Li, W.; Seh, Z.W.; Cui, Y. Amphiphilic Surface Modification of Hollow Carbon Nanofibers for Improved Cycle Life of Lithium Sulfur Batteries. Nano Lett. 2013, 13, 1265-1270. [CrossRef]

150. Gu, X.; Lai, C.; Liu, F.; Yang, W.; Hou, Y.; Zhang, S. A Conductive Interwoven Bamboo Carbon Fiber Membrane for Li-S batteries. J. Mater. Chem. A 2015, 3, 9502-9509. [CrossRef]

151. Liang, C.; Zhang, X.; Zhao, Y.; Tan, T.; Zhang, Y.; Chen, Z. Preparation of Hierarchical Porous Carbon from Waterweed and Its Application in Lithium/Sulfur Batteries. Energies 2018, 11, 1535. [CrossRef]

152. Zhang, J.; Cai, Y.; Zhong, Q.; Lai, D.; Yao, J. Porous Nitrogen-Doped Carbon Derived from Silk Fibroin Protein Encapsulating Sulfur as a Superior Cathode Material for High-Performance Lithium-Sulfur Batteries. Nanoscale 2015, 7, 17791-17797. [CrossRef] [PubMed]

153. Xu, J.; Zhang, W.; Chen, Y.; Fan, H.; Su, D.; Wang, G. MOF-Derived Porous N-Co $\mathrm{O}_{4} @ \mathrm{~N}-\mathrm{C}$ Nanododecahedra Wrapped with Reduced Graphene Oxide as a High Capacity Cathode for Lithium-Sulfur Batteries. J. Mater. Chem. A 2018, 6, 2797-2807. [CrossRef]

154. Campbell, B.; Bell, J.; Bay, H.H.; Favors, Z.; Ionescu, R.; Ozkan, C.S.; Ozkan, M. SiO 2 -Coated Sulfur Particles with Mildly Reduced Graphene Oxide as a Cathode Material for Lithium-Sulfur Batteries. Nanoscale 2015, 7, 7051-7055. [CrossRef]

155. Yu, M.; Ma, J.; Song, H.; Wang, A.; Tian, F.; Wang, Y.; Qiu, H.; Wang, R. Atomic Layer Deposited TiO 2 on a Nitrogen-Doped Graphene/Sulfur Electrode for High Performance Lithium-Sulfur Batteries. Energy Environ. Sci. 2016, 9, 1495-1503. [CrossRef]

156. Su, Z.; Tong, C.J.; He, D.Q.; Lai, C.; Liu, L.M.; Wang, C.; Xi, K. Ultra-small $\mathrm{B}_{2} \mathrm{O}_{3}$ Nanocrystals Grown in Situ on Highly Porous Carbon Microtubes for Lithium-Iodine and Lithium-Sulfur Batteries. J. Mater. Chem. A 2016, 4, 8541-8547. [CrossRef]

157. Tao, Y.; Wei, Y.; Liu, Y.; Wang, J.; Qiao, W.; Ling, L.; Long, D. Kinetically-Enhanced Polysulfide Redox Reactions by $\mathrm{Nb}_{2} \mathrm{O}_{5}$ Nanocrystals for High-Rate Lithium-Sulfur Batter. Energy Environ. Sci. 2016, 9, 3230-3239. [CrossRef]

158. Xie, J.; Li, B.Q.; Peng, H.J.; Song, Y.W.; Zhao, M.; Chen, X.; Zhang, Q.; Huang, J.Q. Implanting Atomic Cobalt within Mesoporous Carbon toward Highly Stable Lithium-Sulfur Batteries. Adv. Mater. 2019, 31, 1903813. [CrossRef] [PubMed]

159. Liu, S.; Li, J.; Yan, X.; Su, Q.; Lu, Y.; Qiu, J.; Wang, Z.; Lin, X.; Huang, J.; Liu, R.; et al. Superhierarchical Cobalt-Embedded Nitrogen-Doped Porous Carbon Nanosheets as Two-in-One Hosts for High-Performance Lithium-Sulfur Batteries. Adv. Mater. 2018, 30, 1706895. [CrossRef] [PubMed]

160. Xiang, M.; Wu, H.; Liu, H.; Huang, J.; Zheng, Y.; Yang, L.; Jing, P.; Zhang, Y.; Dou, S.; Liu, H. A Flexible 3D Multifunctional MgO-Decorated Carbon Foam@CNTs Hybrid as Self-Supported Cathode for High-Performance Lithium-Sulfur Batteries. Adv. Funct. Mater. 2017, 27, 1702573. [CrossRef]

161. Kim, A.Y.; Kim, M.K.; Kim, J.Y.; Wen, Y.; Gu, L.; Dao, V.D.; Choi, H.S.; Byun, D.; Lee, J.K. Ordered SnO Nanoparticles in MWCNT as A Functional Host Material for High-Rate Lithium-Sulfur Battery Cathode. Nano Res. 2017, 10, 2083-2095. [CrossRef]

162. Chen, T.; Zhang, Z.; Cheng, B.; Chen, R.; Hu, Y.; Ma, L.; Zhu, G.; Liu, J.; Jin, Z. Self-Templated Formation of Interlaced Carbon Nanotubes Threaded Hollow Co3S4 Nanoboxes for High-Rate and Heat-Resistant Lithium-Sulfur Batteries. J. Am. Chem. Soc. 2017, 139, 12710-12715. [CrossRef]

163. He, J.; Luo, L.; Chen, Y.; Manthiram, A. Yolk-Shelled C@Fe $\mathrm{O}_{4}$ Nanoboxes as Efficient Sulfur Hosts for High-Performance Lithium-Sulfur Batteries. Adv. Mater. 2017, 29, 1702707. [CrossRef]

164. Chen, M.; Lu, Q.; Jiang, S.; Huang, C.; Wang, X.; Wu, B.; Xiang, X.; Wu, Y. $\mathrm{MnO}_{2}$ Nanosheets Grown on the Internal/External Surface of N-Doped Hollow Porous Carbon Nanospheres as the Sulfur Host of Advanced Lithium-Sulfur Batteries. Chem. Eng. J. 2018, 335, 831-842. [CrossRef]

165. Fang, M.; Chen, Z.; Liu, Y.; Quan, J.; Yang, C.; Zhu, L.; Xu, Q.; Xu, Q. Design and Synthesis of Novel Sandwich-Type

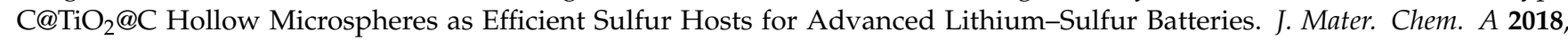
6, 1630-1638. [CrossRef]

166. Song, J.; Xu, T.; Gordin, M.L.; Zhu, P.; Lv, D.; Jiang, Y.B.; Chen, Y.; Duan, Y.; Wang, D. Nitrogen-Doped Mesoporous Carbon Promoted Chemical Adsorption of Sulfur and Fabrication of High-Areal-Capacity Sulfur Cathode with Exceptional Cycling Stability for Lithium-Sulfur Batteries. Adv. Funct. Mater. 2014, 24, 1243-1250. [CrossRef]

167. Zhong, Y.; Lin, F.; Wang, M.; Zhang, Y.; Ma, Q.; Lin, J.; Feng, Z.; Wang, H. Metal Organic Framework Derivative Improving Lithium Metal Anode Cycling. Adv. Funct. Mater. 2020, 30, 1907579. [CrossRef] 
168. Yao, S.; Guo, R.; Xie, F.; Wu, Z.; Gao, K.; Zhang, C.; Shen, X.; Li, T.; Qin, S. Electrospun Three-Dimensional Cobalt Decorated Nitrogen Doped Carbon Nanofibers Network as Freestanding Electrode for Lithium/Sulfur Batteries. Electrochim. Acta 2020, 337, 135765. [CrossRef]

169. Chen, K.; Sun, Z.; Fang, R.; Shi, Y.; Cheng, H.M.; Li, F. Metal-Organic Frameworks (MOFs)-Derived Nitrogen-Doped Porous Carbon Anchored on Graphene with Multifunctional Effects for Lithium-Sulfur Batteries. Adv. Funct. Mater. 2018, 28, 1707592. [CrossRef]

170. Yim, T.; Park, M.S.; Yu, J.S.; Kim, K.J.; Im, K.Y.; Kim, J.H.; Jeong, G.; Jo, Y.N.; Woo, S.G.; Kang, K.S.; et al. Effect of chemical reactivity of polysulfide toward carbonate-basedelectrolyte on the electrochemical performance of Li-S batteries. Electrochim. Acta 2013, 107, 454-460. [CrossRef]

171. Mohan, E.H.; Sarada, B.V.; Naidu, R.V.R.; Salian, G.; Haridasa, A.K.; Rao, B.V.A.; Rao, T.N. Graphene-Modified Electrodeposited Dendritic Porous Tin Structures as Binder Free Anode for High Performance Lithium-Sulfur Batteries. Electrochim. Acta 2016, 219, 701-710. [CrossRef]

172. Yabuuchi, N.; Kubota, K.; Dahbi, M.; Komaba, S. Research Development on Sodium-Ion Batteries. Chem. Rev. 2014, 114, 11636-11682. [CrossRef] [PubMed]

173. Stevens, D.A.; Dahn, J.R. The Mechanisms of Lithium and Sodium Insertion in Carbon Materials. J. Electrochem. Soc. 2001, 148, A803-A811. [CrossRef]

174. Qiu, S.; Xiao, L.; Sushko, M.L.; Han, K.S.; Shao, Y.; Yan, M.; Liang, X.; Mai, L.; Feng, J.; Cao, Y.; et al. Manipulating AdsorptionInsertion Mechanisms in Nanostructured Carbon Materials for High-Efficiency Sodium Ion Storage. Adv. Energy Mater. 2017, 7, 1700403. [CrossRef]

175. Balogun, M.S.; Luo, Y.; Qiu, W.; Liu, P.; Tong, Y. A review of carbon materials and their composites with alloy metals for sodium ion battery anodes. Carbon 2016, 98, 162-178. [CrossRef]

176. Hou, H.; Qiu, X.; Wei, W.; Zhang, Y.; Ji, X. Carbon Anode Materials for Advanced Sodium-Ion Batteries. Adv. Energy Mater. 2017, 7, 1602898. [CrossRef]

177. Ponrouch, A.; Goni, A.R.; Palacin, M.R. High Capacity Hard Carbon Anodes for Sodium Ion Batteries in Additive Free Electrolyte. Electrochem. Commun. 2013, 27, 85-88. [CrossRef]

178. Lotfabad, E.M.; Ding, J.; Cui, K.; Kohandehghan, A.; Kalisvaart, W.P.; Hazelton, M.; Mitlin, D. High-Density Sodium and Lithium Ion Battery Anodes from Banana Peels. ACS Nano 2014, 8, 7115-7129. [CrossRef] [PubMed]

179. Yang, T.; Qian, T.; Wang, M.; Shen, X.; Hu, N.; Sun, Z.; Yan, C. A Sustainable Route from Biomass Byproduct Okara to High Content Nitrogen-Doped Carbon Sheets for Efficient Sodium Ion Batteries. Adv. Mater. 2016, 28, 539-545. [CrossRef] [PubMed]

180. Li, Y.; Paranthaman, M.P.; Akato, K.; Naskar, A.K.; Levine, A.M.; Lee, R.J.; Kim, S.O.; Zhang, J.; Dai, S.; Manthiram, A. Tire-Derived Carbon Composite Anodes for Sodium-Ion Batteries. J. Power Sources 2016, 316, 232-238. [CrossRef]

181. Wang, H.; Yu, W.; Shi, J.; Mao, N.; Chen, S.; Liu, W. Biomass Derived Hierarchical Porous Carbons as High-Performance Anodes for Sodium-Ion Batteries. Electrochim. Acta 2016, 188, 103-110. [CrossRef]

182. Gaddam, R.R.; Jiang, E.; Amiralian, N.; Annamalai, P.K.; Martin, D.J.; Kumar, N.A.; Zhao, X.S. Spinifex Nanocellulose Derived Hard Carbon Anodes for High-Performance Sodium-Ion Batteries. Sustain. Energy Fuels 2017, 1, 1090-1097. [CrossRef]

183. Li, Z.; Chen, Y.; Jain, Z.; Jiang, H.; Razink, J.J.; Stickle, W.F.; Neuefeind, J.C.; Ji, X. Defective Hard Carbon Anode for Na-Ion Batteries. Chem. Mater 2018, 30, 4536-4542. [CrossRef]

184. Luo, W.; Schardt, J.; Bommier, C.; Wang, B.; Razink, J.; Simonsen, J.; Ji, X. Carbon Nanofibers Derived from Cellulose Nanofibers as a Long-Life Anode Material for Rechargeable Sodium-Ion Batteries. J. Mater. Chem. A 2013, 1, 10662-10666. [CrossRef]

185. Rybarczyk, M.K.; Li, Y.; Qiao, M.; Hu, Y.S.; Titirici, M.M.; Lieder, M. Hard Carbon Derived from Rice Husk as Low Cost Negative Electrodes in Na-ion Batteries. J. Energy Chem. 2019, 29, 17-22. [CrossRef]

186. Darjazi, H.; Staffolani, A.; Sbrascini, L.; Bottoni, L.; Tossici, R.; Nobili, F. Sustainable Anodes for Lithium- and Sodium-Ion Batteries Based on Coffee Ground-Derived Hard Carbon and Green Binders. Energies 2020, 13, 6216. [CrossRef]

187. Rios, C.M.S.; Simonin, L.; Geyer, A.; Ghimbeu, C.M.; Dupont, C. Unraveling the Properties of Biomass-Derived Hard Carbons upon Thermal Treatment for a Practical Application in Na-Ion Batteries. Energies 2020, 13, 3513. [CrossRef]

188. Zou, Y.; Li, H.; Qin, K.; Xia, Y.; Lin, L.; Qi, Y.; Jian, Z.; Chen, W. Low-Cost Lignite-Derived Hard Carbon for High-Performance Sodium-Ion Storage. J. Mater. Sci. 2020, 55, 5994-6004. [CrossRef]

189. Luo, W.; Jian, Z.; Xing, Z.; Wang, W.; Bommier, C.; Lerner, M.M.; Ji, X. Electrochemically Expandable Soft Carbon as Anodes for Na-Ion Batteries. ACS Cent. Sci. 2015, 1, 516-522. [CrossRef] [PubMed]

190. Shao, Y.; Xiao, J.; Wang, W.; Engelhard, M.; Chen, X.; Nie, Z.; Gu, M.; Saraf, L.V.; Exarhos, G.; Zhang, J.G.; et al. Surface-Driven Sodium Ion Energy Storage in Nanocellular Carbon Foams. Nano Lett. 2013, 13, 3909-3914. [CrossRef] [PubMed]

191. Li, W.; Zeng, L.; Yang, Z.; Gu, L.; Wang, J.; Liu, X.; Cheng, J.; Yu, Y. Free-Standing and Binder-Free Sodium-Ion Electrodes with Ultralong Cycle Life and High Rate Performance Based on Porous Carbon Nanofibers. Nanoscale 2014, 6, 693-698. [CrossRef]

192. Lu, P.; Sun, Y.; Xiang, H.; Liang, X.; Yu, Y. 3D Amorphous Carbon with Controlled Porous and Disordered Structures as a High-Rate Anode Material for Sodium-Ion Batteries. Adv. Energy Mater. 2017, 1702434. [CrossRef]

193. Wang, H.G.; Wu, Z.; Meng, F.I.; Ma, D.L.; Huang, X.L.; Wang, L.M.; Zhang, X.B. Nitrogen-Doped Porous Carbon Nanosheets as Low-Cost, High-Performance Anode Material for Sodium-Ion Batteries. ChemSusChem 2013, 6, 56-60. [CrossRef] [PubMed]

194. Song, H.; Li, N.; Cui, H.; Wang, C. Enhanced Storage Capability and Kinetic Processes by Pores- and Hetero-Atoms- Riched Carbon Nanobubbles for Lithium-Ion and Sodium-Ion Batteries Anodes. Nano Energy 2014, 4, 81-87. [CrossRef] 
195. Chen, Y.; Li, X.; Park, K.; Lu, W.; Wang, C.; Xue, W.; Yang, F.; Zhou, J.; Suo, L.; Lin, T.; et al. Nitrogen-Doped Carbon for Sodium-Ion Battery Anode by Self-Etching and Graphitization of Bimetallic MOF-Based Composite. Chem. 2017, 3, 152-163. [CrossRef]

196. Zhang, Q.; Zhang, Y.; Liu, S.; Yang, H. Nitrogen-Doped Three-Dimensional Porous Carbon Anode Derived from Hard Halloysite Template for Sodium-Ion Batteries. Appl. Clay. Sci. 2021, 200, 105916. [CrossRef]

197. Wang, Y.X.; Chou, S.L.; Liu, H.K.; Dou, S.X. Reduced Graphene Oxide with Superior Cycling Stability and Rate Capability for Sodium Storage. Carbon 2013, 57, 202-208. [CrossRef]

198. Wen, Y.; He, K.; Zhu, Y.; Han, F.; Hu, Y.; Masuda, I.; Ishii, Y.; Cumings, J.; Wang, C. Expanded Graphite as Superior Anode for Sodium-Ion Batteries. Nat. Commun. 2014, 5, 4033. [CrossRef] [PubMed]

199. Shin, H.J.; Kim, K.K.; Benayad, A.; Yoon, S.M.; Park, H.K.; Jung, I.S.; Jin, M.H.; Jeong, H.K.; Kim, J.M.; Choi, J.Y.; et al. Efficient Reduction of Graphite Oxide by Sodium Borohydride and Its Effect on Electrical Conductance. Adv. Funct. Mater. 2009, 19, 1987-1992. [CrossRef]

200. He, D.; Peng, Z.; Gong, W.; Luo, Y.; Zhao, P.; Kong, L. Mechanism of a Green Graphene Oxide Reduction with Reusable Potassium Carbonate. RSC Adv. 2015, 5, 11966-11972. [CrossRef]

201. Kumar, N.A.; Gambarelli, S.; Duclairoir, F.; Bidan, G.; Dubois, L. Synthesis of High Quality Reduced Graphene Oxide Nanosheets Free of Paramagnetic Metallic Impurities. J. Mater. Chem. A 2013, 1, 2789-2794. [CrossRef]

202. Kumar, N.A.; Togami, M.; Oishi, Y.; Tominaga, M.; Takafuji, M.; Ihara, H. Iron Metal Induced Deoxygenation of Graphite Oxide Nanosheets-Insights on the Capacitive Properties of Binder-Free Electrodes. RSC Adv. 2015, 5, 23367-23373. [CrossRef]

203. Kumar, N.A.; Gaddam, R.R.; Varanasi, S.R.; Yang, D.; Bhatia, S.K.; Zhao, X.S. Sodium Ion Storage in Reduced Graphene Oxide. Electrochim. Acta 2016, 214, 319-325. [CrossRef]

204. Aslam, M.K.; Xu, M. A Mini-Review: MXene Composites for Sodium/Potassium-Ion Batteries. Nanoscle 2020, 12, 15993-16007. [CrossRef] [PubMed]

205. Darwiche, A.; Marino, C.; Sougrati, M.T.; Fraisse, B.; Stievano, L.; Monconduit, L. Better Cycling Performances of Bulk Sb in Na-Ion Batteries Compared to Li-Ion Systems: An Unexpected Electrochemical Mechanism. J. Am. Chem. Soc. 2012, 134, 20805-20811. [CrossRef] [PubMed]

206. Zhu, H.; Jia, Z.; Chen, Y.; Weadock, N.; Wan, J.; Vaaland, O.; Han, X.; Li, T.; Hu, L. Tin Anode for Sodium-Ion Batteries Using Natural Wood Fiber as a Mechanical Buffer and Electrolyte Reservoir. Nano Lett. 2013, 13, 3093-3100. [CrossRef] [PubMed]

207. Luo, C.; Xu, Y.; Zhu, Y.; Liu, Y.; Zheng, S.; Liu, Y.; Langrock, A.; Wang, C. Selenium@Mesoporous Carbon Composite with Superior Lithium and Sodium Storage Capacity. ACS Nano 2013, 7, 8003-8010. [CrossRef]

208. Mei, Y.; Huang, Y.; Hu, X. Nanostructured Ti-based Anode Materials for Na-ion Batteries. J. Mater. Chem. A 2016, 4, 12001-12013. [CrossRef]

209. Wang, N.; Chu, C.; Xu, X.; Du, Y.; Yang, J.; Bai, Z.; Dou, S. Comprehensive New Insights and Perspectives into Ti-Based Anodes for Next-Generation Alkaline Metal $\left(\mathrm{Na}^{+}, \mathrm{K}^{+}\right)$Ion Batteries. Adv. Energy Mater. 2018, 1800888. [CrossRef]

210. Lee, Y.H.; Luu, T.H.T.; Duong, D.L.; Lee, T.H.; Pham, D.T.; Shaoo, R.; Han, G.; Kim, Y.M.; Lee, Y.H. Monodispersed SnS Nanoparticles Anchored on Carbon Nanotubes for High-Retention Sodium-Ion Batteries. J. Mater. Chem. A 2020, 8, 7861-7869. [CrossRef]

211. Chen, B.; Qin, H.; Li, K.; Zhang, B.; Liu, E.; Zhao, N.; Shi, C.; He, C. Yolk-shelled Sb@C Nanoconfined Nitrogen/Sulfur CoDoped 3D Porous Carbon Microspheres for Sodium-Ion Battery Anode with Ultralong High-Rate Cycling. Nano Energy 2019, 66, 104133. [CrossRef]

212. Schulze, M.C.; Belson, R.M.; Kraynak, L.A.; Prieto, A.L. Electrodeposition of Sb/CNT Composite Films as Anodes for Li- and Na-Ion Batteries. Energy Stor. Mater. 2020, 25, 572-584. [CrossRef]

213. Peng, B.; Xu, Y.; Wang, X.; Mulder, F.M. A High Performance and Low Cost Sodium Ion Anode Based on A Facile Black Phosphorus-Carbon Nanocomposite. ChemElectroChem 2017, 4, 2140-2144. [CrossRef]

214. Wang, Y.; Niu, P.; Li, J.; Wang, S.; Li, L. Recent Progress of Phosphorus Composite Anodes for Sodium/Potassium Ion Batteries. Energy Stor. Mater. 2021, 34, 436-460. [CrossRef]

215. Lu, Y.C.; Dimov, N.; Okada, S.; Bui, T.H. SnSb Alloy Blended with Hard Carbon as Anode for Na-Ion. Batteries Energies 2018, 11, 1614. [CrossRef]

216. Cha, H.A.; Jeong, H.M.; Kang, J.K. Nitrogen-Doped Open Pore Channeled Graphene Facilitating Electrochemical Performance of $\mathrm{TiO}_{2}$ Nanoparticles as an Anode Material for Sodium Ion Batteries. J. Mater. Chem. A 2014, 2, 5182-5186. [CrossRef]

217. Jin, H.; Zhang, T.; Chuang, C.; Lu, Y.R.; Chan, T.S.; Du, Z.; Ji, H.; Wan, L.J. Synergy of Black Phosphorus-Graphite-PolyanilineBased Ternary Composites for Stable High Reversible Capacity Na-Ion Battery Anodes. ACS Appl. Mater. Interfaces 2019, 11, 16656-16661. [CrossRef]

218. Liu, T.; Zhang, F.; Song, Y.; Li, Y. Revitalizing Carbon Supercapacitor Electrodes with Hierarchical Porous Structures. J. Mater. Chem. A 2017, 5, 17705-17733. [CrossRef]

219. Łukaszewski, M.; Hubkowska, K.; Koss, U.; Czerwiński, A. Characteristic of Hydrogen-Saturated Pd-Based Alloys for the Application in Electrochemical Capacitors. J. Solid State Electrochem. 2012, 16, 2533-2539. [CrossRef]

220. Sharma, K.; Arora, A.; Tripathia, S.K. Review of Supercapacitors: Materials and Devices. J. Energy Storage 2019, $21,801-825$.

221. Ho, M.Y.; Khiew, P.S.; Isa, D.; Tan, T.K.; Chiu, W.S.; Chia, C.H. A review of Metal Oxide Composite Electrode Materials for Electrochemical Capacitors. Nano 2014, 9, 1430002. [CrossRef]

222. Wang, Q.; Yan, J.; Fan, Z. Carbon Materials for High Volumetric Performance Supercapacitors: Design, Progress, Challenges and Opportunities. Energy Environ. Sci. 2016, 9, 729-762. [CrossRef] 
223. Dubey, R.; Guruviah, V. Review of Carbon-Based Electrode Materials for Supercapacitor Energy Storage. Ionics 2019, 25, 1419-1445. [CrossRef]

224. Fuertes, A.B.; Lota, G.; Centeno, T.A.; Frackowiak, E. Templated Mesoporous Carbons for Supercapacitor Application. Electrochim. Acta 2005, 50, 2799-2805. [CrossRef]

225. Béguin, F.; Presser, V.; Balducci, A.; Frackowiak, E. Carbons and Electrolytes for Advanced Supercapacitors. Adv. Mater. 2014, 26, 2219-2251. [CrossRef]

226. Zhong, H.; Xu, F.; Li, Z.; Fu, R.; Wu, D. High-Energy Supercapacitors Based on Hierarchical Porous Carbon with an Ultrahigh Ion-Accessible Surface Area in Ionic Liquid Electrolytes. Nanoscale 2013, 5, 4678-4682. [CrossRef] [PubMed]

227. Bi, Z.; Kong, Q.; Cao, Y.; Sun, G.; Su, F.; Wei, X.; Li, X.; Ahmad, A.; Xie, L.; Chen, C.M. Biomass-Derived Porous Carbon Materials with Different Dimensions for Supercapacitor Electrodes: A Review. J. Mater. Chem. A 2019, 7, 16028. [CrossRef]

228. Yang, Z.; Tian, J.; Yin, Z.; Cui, C.; Qian, W.; Wei, F. Carbon Nanotube-and Graphene-Based Nanomaterials and Applications in High-Voltage Supercapacitor: A Review. Carbon 2019, 141, 467-480. [CrossRef]

229. Borenstein, A.; Hanna, O.; Attias, R.; Luski, S.; Brousse, T.; Aurbach, D. Carbon-Based Composite Materials for Supercapacitor Electrodes: A Review. J. Mater. Chem. A 2017, 5, 12653-12672. [CrossRef]

230. Frackowiak, E.; Abbas, Q.; Béguin, F. Carbon/Carbon Supercapacitors. J. Energy Chem. 2013, 22, 226-240. [CrossRef]

231. Chien, H.C.; Cheng, W.Y.; Wang, Y.H.; Lu, S.Y. Ultrahigh Specific Capacitances for Supercapacitors Achieved by Nickel Cobaltite/Carbon Aerogel Composites. Adv. Funct. Mater. 2012, 22, 5038-5043. [CrossRef]

232. Levitt, A.S.; Alhabeb, M.; Hatter, C.B.; Sarycheva, A.; Dion, G.; Gogotsi, Y. Electrospun MXene/Carbon Nanofibers as Supercapacitor Electrodes. J. Mater. Chem. A 2019, 7, 269. [CrossRef]

233. Pan, H.; Li, J.; Feng, Y.P. Carbon Nanotubes for Supercapacitor. Nanoscale Res. Lett. 2010, 5, 654-668. [CrossRef]

234. Xu, B.; Yue, S.; Sui, Z.; Zhang, X.; Hou, S.; Cao, G.; Yang, Y. What is the Choice for Supercapacitors: Graphene or Graphene Oxide? Energy Environ. Sci. 2011, 4, 2826-2830. [CrossRef]

235. Luo, H.; Liu, Z.; Chao, L.; Wu, X.; Lei, X.; Chang, Z.; Sun, X. Synthesis of Hierarchical Porous N-doped Sandwich-Type Carbon Composites as High-Performance Supercapacitor Electrodes. J. Mater. Chem. A 2015, 3, 3667-3675. [CrossRef]

236. Pech, D.; Brunet, M.; Durou, H.; Huang, P.; Mochalin, V.; Gogotsi, Y.; Taberna, P.L.; Simon, P. Ultrahigh-Power Micrometre-Sized Supercapacitors based on Onion-Like Carbon. Nat. Nanotechnol. 2010, 5, 651-654. [CrossRef]

237. Simon, P.; Gogotsi, Y. Materials for Electrochemical Capacitors. Nat. Mater. 2008, 7, 845-854. [CrossRef]

238. Lv, L.; Fan, Y.; Chen, Q.; Zhao, Y.; Hu, Y.; Zhang, Z.; Chen, N.; Qu, L. Three-Dimensional Multichannel Aerogel of Carbon Quantum Dots for High-Performance Supercapacitors. Nanotechnology 2014, 25, 235401. [CrossRef] [PubMed]

239. Strauss, V.; Marsh, H.; Kowal, M.D.; El-Kady, M.; Kaner, R.B. A Simple Route to Porous Graphene from Carbon Nanodots for Supercapacitor Applications. Adv. Mater. 2018, 30, 1704449. [CrossRef] [PubMed]

240. Kumar, V.B.; Borenstein, A.; Markovsky, B.; Aurbach, D.; Gedanken, A.; Talianker, M.; Porat, Z. Activated Carbon Modified with Carbon Nanodots as Novel Electrode Material for Supercapacitors. J. Phys. Chem. C 2016, 120, 13406-13413. [CrossRef]

241. Hu, Y.; Zhao, Y.; Lu, G.; Chen, N.; Zhang, Z.; Li, H.; Shao, H.; Qu, L. Graphene Quantum Dots-Carbon Nanotube Hybrid Arrays for Supercapacitors. Nanotechnology 2013, 24, 195401. [CrossRef]

242. ] Niu, Y.; Wang, J.; Zhang, J.; . Shi, Z. Graphene Quantum Dots as a Novel Conductive Additive to Improve the Capacitive Performance for Supercapacitors. J. Electroanal. Chem. 2018, 828, 1-10. [CrossRef]

243. Qiu, Y.; Li, G.; Hou, Y.; Pan, Z.; Li, H.; Li, W.; Liu, M.; Ye, F.; Yang, X.; Zhang, Y. Vertically Aligned Carbon Nanotubes on Carbon Nanofibers: A Hierarchical Three-Dimensional Carbon Nanostructure for High-Energy Flexible Supercapacitors. Chem. Mater. 2015, 27, 1194-1200. [CrossRef]

244. Chen, Y.; Zhang, X.; Zhang, H.; Sun, H.; Zhang, D.; Ma, Y. High-Performance Supercapacitors Based on a Graphene-Activated Carbon Composite Prepared by Chemical Activation. RSC Adv. 2012, 2, 7747-7753. [CrossRef]

245. Kim, T.; Jung, G.; Yoo, S.; Suh, K.S.; Ruoff, R.S. Activated Graphene-Based Carbons as Supercapacitor Electrodes with Macro- and Mesopores. ACS Nano 2013, 7, 6899-6905. [CrossRef]

246. Li, X.; Tang, Y.; Song, J.; Yang, W.; Wang, M.; Zhu, C.; Zhao, W.; Zheng, J.; Lin, Y. Self-Supporting Activated Carbon/Carbon Nanotube/Reduced Graphene Oxide Flexible Electrode for High Performance Supercapacitor. Carbon 2018, 129, 236-244. [CrossRef]

247. Wang, X.; Liu, C.G.; Neff, D.; Fulvio, P.; Mayes, R.; Zhamu, A.; Fang, Q.; Chen, G.; Meyer III, H.; Jang, B.; et al. Nitrogen-enriched Ordered Mesoporous Carbons Through Direct Pyrolysis in Ammonia with Enhanced Capacitive Performance. J. Mater. Chem. A 2013, 1, 7920-7926. [CrossRef]

248. Chen, H.; Sun, F.; Wang, J.; Li, W.; Qiao, W.; Ling, L.; Long, D. Nitrogen Doping Effects on the Physical and Chemical Properties of Mesoporous Carbons. J. Phys. Chem. C 2013, 117, 8318-8328. [CrossRef]

249. Ramirez-Castro, C.; Crosnier, O.; Athouel, L.; Retoux, R.; Belanger, D.; Brousse, T. Electrochemical Performance of Carbon $/ \mathrm{MnO}_{2}$ Nanocomposites Prepared via Molecular Bridging as Supercapacitor Electrode Materials. J. Electrochem. Soc. 2015, 162, A5179-A5184. [CrossRef]

250. Lv, H.; Yuan, Y.; Xu, Q.; Liu, H.; Wang, Y.G.; Xia, Y. Carbon Quantum Dots Anchoring $\mathrm{MnO}_{2} /$ Graphene Aerogel Exhibits Excellent Performance as Electrode Materials for Supercapacitor. J. Power Sources 2018, 398, 167-174. [CrossRef]

251. Li, L.; Hu, Z.A.; An, N.; Yang, Y.Y.; Li, Z.M.; Wu, H.Y. Facile Synthesis of $\mathrm{MnO}_{2} / \mathrm{CNTs}$ Composite for Supercapacitor Electrodes with Long Cycle Stability. J. Phys. Chem. C 2014, 118, 22865-22872. [CrossRef] 
252. Noh, J.; Yoon, C.M.; Kim, Y.K.; Jang, J. High Performance Asymmetric Supercapacitor Twisted from Carbon Fiber $/ \mathrm{MnO}_{2}$ and Carbon Fiber $/ \mathrm{MoO}_{3}$. Carbon 2017, 116, 470-478. [CrossRef]

253. Warren, R.; Sammoura, F.; Tounsi, F.; Sanghadasa, M.; Lin, L. Highly Active Ruthenium Oxide Coating via ALD and Electrochemical Activation in Supercapacitor Applications. J. Mater. Chem. A 2015, 3, 15568-15575. [CrossRef]

254. He, G.; Li, J.; Chen, H.; Shi, J.; Sun, X.; Chen, S.; Wang, X. Hydrothermal Preparation of $\mathrm{Co}_{3} \mathrm{O}_{4} @$ graphene Nanocomposite for Supercapacitor with Enhanced Capacitive Performance. Mater. Lett. 2012, 82, 61-63. [CrossRef]

255. Fleker, O.; Borenstein, A.; Lavi, R.; Benisvy, L.; Ruthstein, S.; Aurbach, D. Preparation and Properties of Metal Organic Framework/Activated Carbon Composite Materials. Langmuir 2016, 32, 4935-4944. [CrossRef]

256. Panda, B.; Dwivedi, I.; Priya, K.; Karandikar, P.B.; Mandake, P.S. Analysis of Aqueous Supercapacitor with Various Current Collectors, Binders and Adhesives. In Proceedings of the 2016 Biennial International Conference on Power and Energy Systems: Towards Sustainable Energy (PESTSE 2016), Bengaluru, India, 21-23 January 2016.

257. Talapatra, S.; Kar, S.; Pal, S.K.; Vajtai, R.; Ci, L.; Victor, P.; Shaijumon, M.M.; Kaur, S.; Nalamasu, O.; Ajayan, P.M. Direct growth of aligned carbon nanotubes on bulk metals. Nat. Nanotechnol. 2006, 1, 112-116. [CrossRef]

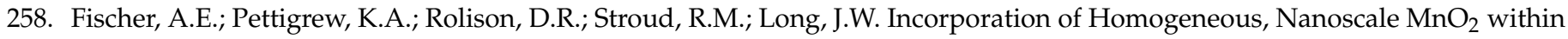
Ultraporous Carbon Structures via Self-Limiting Electroless Deposition: Implications for Electrochemical Capacitors. Nano Lett. 2007, 7, 281-286. [CrossRef]

259. Futaba, D.N.; Hata, K.; Yamada, T.; Hiraoka, T.; Hayamizu, Y.; Kakudate, Y.; Tanaike, O.; Hatori, H.; Yumura, M.; Iijima, S. Shape-Engineerable and Highly Densely Packed Single-Walled Carbon Nanotubes and their Application as Super-Capacitor Electrodes. Nat. Mater. 2006, 5, 987-994. [CrossRef] [PubMed]

260. Chen, P.; Chen, H.; Qiu, J.; Zhou, C. Inkjet Printing of Single-Walled Carbon Nanotube/ $\mathrm{RuO}_{2}$ Nanowire Supercapacitors on Cloth Fabrics and Flexible Substrates. Nano Res. 2010, 3, 594-603. [CrossRef]

261. Vangari, M.; Pryor, T.; Jiang, L. Supercapacitors: Review of Materials and Fabrication Methods. J. Energy Eng. 2013, 139, 72-79. [CrossRef]

262. Kaempgen, M.; Chan, C.K.; Ma, J.; Cui, Y.; Gruner, G. Printable Thin Film Supercapacitors Using Single-Walled Carbon Nanotubes. Nano Lett. 2009, 9, 1872-1876. [CrossRef] [PubMed]

263. Zheng, G.; Hu, L.; Wu, H.; Xie, X.; Cui, Y. Paper Supercapacitors by a Solvent-Free Drawing Method. Energy Environ. Sci. 2011, 4, 3368-3373. [CrossRef]

264. Hoffmann, V.; Jung, D.; Alhnidi, M.J.; Mackle, L.; Kruse, A. Bio-Based Carbon Materials from Potato Waste as Electrode Materials in Supercapacitors. Energies 2020, 13, 2406. [CrossRef]

265. Liu, D.; Zhang, W.; Lin, H.; Li, Y.; Lu, H.; Wang, Y. Hierarchical Porous Carbon Based on the Self-Templating Structure of Rice Husk for High-Performance Supercapacitors. RSC Adv. 2015, 5, 19294-19300. [CrossRef]

266. Yeleuov, M.; Seidl, C.; Temirgaliyeva, T.; Taurbekov, A.; Prikhodko, N.; Lesbayev, B.; Sultanov, F.; Daulbayev, C.; Kumekov, S. Modified Activated Graphene-Based Carbon Electrodes from Rice Husk for Supercapacitor Applications. Energies 2020, 13, 4943. [CrossRef]

267. Li, X.; Liu, L.; Wang, X.; Ok, Y.S.; Elliott, J.A.W.; Chang, S.X.; Chung, H.J. Flexible and Self-Healing Aqueous Supercapacitors for Low Temperature Applications: Polyampholyte Gel Electrolytes with Biochar Electrodes. Sci. Rep. 2017, 7, 1685. [CrossRef] [PubMed]

268. Su, X.L.; Chen, J.R.; Zheng, G.P.; Yang, J.H.; Guan, X.X.; Liua, P.; Zheng, X.C. Three-Dimensional Porous Activated Carbon Derived from Loofah Sponge Biomass for Supercapacitor Applications. Appl. Surf. Sci. 2018, 436, 327-336. [CrossRef]

269. Jia, H.; Sun, J.; Xie, X.; Yin, K.; Sun, L. Cicada Slough-Derived Heteroatom Incorporated Porous Carbon for Supercapacitor: Ultra-High Gravimetric Capacitance. Carbon 2019, 143, 309-317. [CrossRef] 